\title{
The Impact of Simple Institutions in
}

\section{Experimental Economies with Poverty Traps}

\author{
C. Mónica Capra, Tomomi Tanaka, Colin F. Camerer, Lauren Munyan, \\ Veronica Sovero, Lisa Wang, and Charles Noussair ${ }^{1}$
}

\begin{abstract}
:
The existence of multiple equilibria is one explanation for why some countries are rich while others are poor. This explanation also allows the possibility that changes in political and economic institutions might help poor countries "jump" from a bad economic equilibrium into a better one, permanently increasing their output and income. Experiments are a useful methodology to study the effect of institutions on economic growth. In this paper, we study a simple experimental economy in which agents produce output in each period and can allocate the output between consumption and investment (the experiment adds to the design of Lei and Noussair, 2002, 2003). Capital productivity is higher if total investment is above a threshold. The threshold externality generates two equilibria - a suboptimal "poverty trap" and an optimal "rich country" equilibrium - which differ by a factor of around three in the income they create. In baseline sessions, in which agents make independent decisions in a decentralized manner, the economies typically sink into the poverty trap and the optimal equilibrium is never reached. However, the ability to communicate before investing, or to vote on binding "industrial policy" proposals, improves average earnings. Communication enables agents to agree to restrain consumption to cross the capital threshold, and voting enables them to enforce such plans. Combining both of these simple institutions enables all of the economies to escape the poverty trap. This experimental environment constitutes a platform onto which more complex features can be added in a program of experimental growth economics.

JEL Codes: O41, P16, C92

Keywords: Economic growth, development, experimental economics, institutions, political economy

\footnotetext{
${ }^{1} 28$ February 2005. Capra and Noussair: Department of Economics. Emory University, 1602 Fishburne Dr, Atlanta, GA 30322-2240, USA. Camerer, Munyan, Sovero, Tanaka, and Wang: Department of Economics, Division of the Humanities and Social Sciences, Baxter Hall 228-77, California Institute of Technology, Pasadena, CA 91125, USA. We gratefully acknowledge financial support from Emory University and the California Institute of Technology (internal grants). We thank audiences at George Mason, McGill, Caltech, the ESA Regional Meetings in Tucson, Arizona (November 2004) and the International Meeting on Experimental and Behavioral Economics in Cordoba, Spain (December 2004), for useful comments. Vivian Lei and Kenneth Matheny provided many great ideas about how growth can be studied in the lab. Please send correspondence to: C. Mónica Capra, Dept. Economics, Emory Univ., 1602 Fishburne Drive, Atlanta GA 30322-2240 USA.
} 


\section{Introduction}

Why are some countries rich while others are poor? There are many possible explanations, including differences in resources or geography, openness to international trade $^{2}$, economic and political systems ${ }^{3}$, income and wealth inequality, ${ }^{4}$ country-specific cultural $^{5}$ and historical factors ${ }^{6}$, and a multiplicity of equilibria. ${ }^{7}$ In fact, there is no shortage of possible explanations for cross-country disparities in economic growth; the problem is that there are too many plausible explanations, which are hard to clearly separate with available field data. Thus, while macroeconomists have learned much from field data, there are limits on their quality and quantity, so new types of data might be of potential use in investigating the nature of economic growth.

This paper illustrates how new data for the study of economic growth can be generated from experimental political economies. ${ }^{8}$ The economies we study here have two equilibria, a poverty trap and an optimal steady state. This multiplicity of equilibrium is due to a productivity boost when aggregate capital reaches a critical threshold. Since theory gives little guidance about whether and which one of the two equilibria emerges reliably, and how institutions might influence equilibrium selection, empirical observations are useful. In discerning about a related topic ${ }^{9}$, Lucas (1986) suggested that experiments can help economists understand what happens when economic theory does not select one of many equilibria. He wrote:

[since] economic theory does not resolve the question....It is hard to see what can advance the discussion short of assembling a collection of people, putting them in the situation of interest, and observing what they do. (p. 421)

\footnotetext{
${ }^{2}$ E.g., Sachs and Warner (1995, 2001).

${ }^{3}$ E.g., Baumol (1986), Barro and Sala-i-Martin (1995), and Barro (1997).

${ }^{4}$ E.g., Alesina and Rodrik (1994)

${ }^{5}$ E,g. Knack and Keefer (1997).

${ }^{6}$ E.g., Acemoglu et al. (2001).

${ }^{7}$ E.g., Rosenstein-Rodan (1943), Murphy, Shleifer and Vishny (1989).

${ }^{8}$ In a related direction, Cardenas and Carpenter (2004) use field experiments to measure parameters such as social capital and risk preferences to study development in small societies (i.e., villages). See also Angrist et al, (2002); and Ashraf, Karlan and Zin (2004).

${ }^{9}$ Lucas was referring to macroenvironments in which rational expectations allows multiple inflationary paths, and adaptive expectations predict a single path. But the same argument can be applied to any game or economy with multiple equilibra, where theory does not provide an overwhelming argument for emergence of one equilibrium over another.
} 
Following Lucas's suggestion, we construct experimental macroeconomies and observe what people do. Output, welfare, and consumption in many replications of these economies are then compared with theoretical benchmarks. We also study how "institutions" - changes in the rules governing what agents can say and do-affect economic outcomes, and whether these institutions influence equilibrium selection.

Of course, experiments like these are much simpler than the naturally occurring economies we hope to eventually understand. Despite their simplicity, experiments have some merits in studying growth and institutions. In naturally occurring economies, institutions and institutional changes typically arise endogenously, rather than randomly, so that there is an endogeneity problem in inferring whether institutional changes influence growth. ${ }^{10}$ In experimental economies, endogeneity bias can be erased because institutions can be added and subtracted randomly under experimental control. In naturally occurring political economies, different institutions also tend to co-occur in clusters (for example, democratic voting and freedom of the press); this multicollinearity makes it difficult to isolate each institution's separate effect. In contrast, in experiments, institutions can be changed one at a time to establish their separate effects, and can be mixed and matched to create hybrids that do not naturally occur (e.g. dictatorships with a free press). ${ }^{11}$

Our experimental environment is an extension of the optimal growth model of Ramsey (1928), Cass (1965), and Koopmans (1965), and is well understood theoretically. The crucial extension is a threshold externality in capital productivity - there is a level of aggregate capital at which capital productivity jumps sharply. This threshold creates two equilibria. The better equilibrium gives every agent higher consumption and higher utility (which means higher dollar earnings for participants) than the worse equilibrium, which we call a technological poverty trap. ${ }^{12}$ The parametric structure of the economy and the initial

\footnotetext{
${ }^{10}$ See Temple (1999), Islam (2003) or Durlauf and Quah (1999) for a discussion of empirical methodology and results with regard to international comparisons of rates of economic growth.

${ }^{11}$ Plott and George (1992) did experiments on one-period goods markets with two competitive equilibria. Duffy and Fisher (2004) studied a laboratory environment where random "sunspots" induce multiplicity of equilibria.

12 Originally attributed to Rosenstein-Rodan (1943), the idea that multiple equilibria exist has led to a variety of growth models with multiple equilibria. For instance, Azariadis and Drazen (1990) construct an overlapping generations model with two stable Pareto-ranked equilibria. In the inferior equilibrium, no agent trades with members of other generations. Murphy et al. (1989) build a model with synergies among industries, where each industry is profitable only if other industries operate. There are Pareto-dominant equilibria where all of the industries operate and dominated equilibria where none operate. Galor and Zeira (1993) and Banerjee et al.
} 
endowments are chosen so that the poverty trap is likely to be reached; indeed, in these baseline cases, economies never fully escape the poverty trap. Then, we add simple institutions to the baseline economy and determine whether these institutions enable economies to escape the poverty trap.

The first institution we consider is a highly stylized version of "freedom of expression" in which all agents are allowed to engage in communication, unrestricted in content, in a "chat room" before each investment period. In principle, communication can enable agents to coordinate investment to cross the capital threshold. In many cases, communication also improves coordination onto Pareto-dominant equilibria in experimental games in many cases (see Camerer, 2003, chapter 7). Recording the chat messages also allows us to "eavesdrop" on what agents are thinking, which is often insightful.

The second institution is a highly stylized version of a democratic voting process, like voting for an "industrial policy". In each round, two agents are chosen randomly to submit a proposal specifying the quantity that each agent will consume and invest. The citizen/agents vote for proposals and the one elected by the majority is automatically implemented. Finally, a third institution combines the communication and voting treatments to see if they interact (e.g., agents might discuss the merits of different policies before voting or submitting proposals). The focus of our analysis is whether these economies sink into the poverty trap or escape it, and whether communication, voting, and the combination of the two affect economic outcomes.

Since these experiments are the first to explore the effect of institutions on economic growth, we deliberately chose an environment familiar to growth economists, in the hope of initiating dialogue about what experimental data can tell us about growth. We also deliberately began with a simple setup that can be complicated in future experiments (a method used in all successful laboratory sciences). Starting with a more complicated design would be less likely to produce reliable results, and would make it more difficult to know what factors caused outcomes. Because the design is simple, the manner in which we create "free expression" and "democratic voting" captures few of the complexities of these

(2001) show that inequality and the resulting differential access to credit can keep an economy in a Paretodominated equilibrium. See Azariadis (1993) and Cooper (2002) for a detailed treatment of the principal analytical issues in growth models with multiple equilibria. 
institutions when they occur naturally. Furthermore, the fact that readers of this article can probably imagine many different versions of these institutions, or other design features, which are worthy of study, is evidence that the general design can be fruitfully used as part of a research program. This paper is just the start of such a program.

The next section describes the experimental economy, the theoretical predictions, and the procedures of the experiment. In section three the results are reported. Section four is a summary and lists ideas for future research.

\section{The experimental environment, competitive equilibria, and procedures}

\subsection{The environment}

We adopted the multiple equilibrium environment of Lei and Noussair's (2003) study. ${ }^{13}$ At the aggregate level, the economy may be thought of as populated by an infinitelylived representative consumer with a lifetime utility given by:

$$
\sum_{t=0}^{\infty}(1+\rho)^{-t} U\left(C_{t}\right)
$$

$\rho$ is the discount rate, $C_{t}$ is the quantity of consumption at time $t$, and $U\left(C_{t}\right)$ is the representative consumer's utility of consumption. Alternatively, the expression in equation (1) may be thought of as the total value that an infinitely-lived group of agents receives from consumption. The economy faces a resource constraint:

$$
C_{t}+K_{t+1} \leq A * F\left(K_{t}\right)+(1-\delta) K_{t},
$$

with

$$
A=\left\{\begin{array}{ll}
\underline{A}, & \text { if } K<\hat{K} \\
\bar{A}, & \text { if } K \geq \hat{K}
\end{array} .\right.
$$

$\delta$ is the depreciation rate, $K_{t}$ is the economy's aggregate capital stock at the beginning of period $t$, and $A$ is an efficiency parameter on the production technology. The value of $A$ depends on the current level of capital stock in the economy. $A$ has the value $\bar{A}$ above a threshold level of capital stock, $\hat{K}$, and has the value $\underline{A}$ below $\hat{K}$, with $\underline{A}<\bar{A}$. The threshold

\footnotetext{
${ }^{13}$ Lei and Noussair (2003) study an economy with the same parametric structure as the economies studied here. However, the two studies differ in that Lei and Noussair used double auction markets (Smith, 1962) rather than call markets, described in section 2.3.4, to exchange output. They also do not include the insitutional structures, described in section 2.4, that serve as the primary focus of this study.
} 
can be interpreted as a positive externality in production, generated by a sufficiently large aggregate quantity of capital stock in the economy. ${ }^{14}$ Table 1 lists the numerical parameters of the experimental economy.

[Table 1: About here]

In the experiment, the aggregate production capability and the value of consumption of units of output are divided among five heterogeneous agents populating the economy. Each subject $i$ is given two individual production schedules that show how capital $k_{t}^{i}$ is transformed into output $A^{*} f^{i}\left(k_{t}^{i}\right)$, depending on whether total capital $K_{t}=\sum_{i} k_{t}^{i}$ is above or below the threshold of 31 . The marginal utility of consumption of agent $i$ is a discrete approximation of $v^{i}\left(c_{t}^{i}\right)=396+4 i-20 c_{t}^{i}$. The utility function for consumption is expressed in terms of an experimental currency called "Yen," which is converted into US dollars at the end of the experiment at a predetermined, privately-known exchange rate. Agents' utility and production functions were private information. The economy's aggregate production and demand curves are shown in Figure 1. Keep in mind, however, that each subject had different privately-known curves, and no subject directly saw the aggregate curves shown in Figure 1.

\section{[Figure 1: About Here]}

\subsection{Competitive equilibria}

In this economy, there are two stationary stable rational expectations competitive equilibria. One of these equilibria is also an optimal steady state. The optimal steady state is the outcome the economy would asymptotically converge to if it were under the direction of a benevolent social planner. Such a planner would choose $C_{1} \ldots, C_{\infty}$ to maximize (1), subject to (2), (3), and the constraints that $C_{t} \geq 0, K_{t} \geq 0$ and $K_{t+1} \geq(1-\delta) K_{t}$ (gross investment in every period must be non-negative). Table 2 shows the values of the key variables in the

\footnotetext{
${ }^{14}$ See Azariadis (1993) and Azariadis and Drazen (1990) for discussion of growth models with a threshold externality in production.
} 
Pareto-dominant equilibrium (the optimal steady state) ${ }^{15}$ and the Pareto-dominated equilibrium (the poverty trap).

[Table 2: About here]

\subsection{Procedures}

\subsubsection{General procedures}

The experiment consisted of a total of 21 sessions. There were four treatments in the experiment, which differ only by their institutional structures. The four treatments are called baseline, communication, voting, and hybrid (each is described in more detail later). Subjects were undergraduates at Emory University and the California Institute of Technology. Table 3 details when and where sessions were conducted, and average earnings. ${ }^{16}$ Subjects participated in this experiment only once (though many had been in other, unrelated experiments). The next three subsections briefly describe the experiment.

[Table 3: About here]

\subsubsection{Timing within a session}

Five agents participated in each session and were grouped togetner in the same economy. In each session, the experimenter distributed instructions, read them aloud, and conducted a three-period practice horizon (which did not count toward subjects' earnings).

\footnotetext{
${ }^{15}$ The optimal equilibrium capital/consumption combination, $\left(K_{t}, C_{t}\right)=(45,70)$, has the property that from any initial level of capital stock $K_{0}>0$, including $K_{0}=9$, the optimal sequence of consumption and investment decisions of a hypothetical benevolent social planner converges asymptotically to $(45,70)$. At an initial capital level of $K_{t}=25$, the optimal sequence is a constant level of capital and consumption of $(45,70)$. Thus, $\left(K_{t}, C_{t}\right)=$ $(45,70)$ is an optimal steady state for our economies. At this optimal steady state, which is a Pareto-optimal competitive equilibrium for our decentralized economies, each agent consumes 14 units per period for an economy-wide total of 70 units of consumption, and the capital stock is distributed among the agents in the following manner: $\bar{k}^{1}=12, \bar{k}^{2}=9, \bar{k}^{3}=6, \bar{k}^{4}=8$, and $\bar{k}^{5}=10$, where $\bar{k}^{i}$ is the equilibrium capital holding of agent $i$, yielding a total of 45 units. At the Pareto inferior equilibrium agents 1 to 4 each consume 3 units and agent 5 consumes 4 units per period for a total consumption of 16. The allocation of capital stock in this equilibrium is $\bar{k}^{1}=1, \bar{k}^{2}=2, \bar{k}^{3}=1, \bar{k}^{4}=2$, and $\bar{k}^{5}=3$, yielding a total equilibrium capital stock of 9 units.

${ }^{16}$ All sessions were conducted in dedicated experimental laboratories at the two universities. Subjects were paid an initial fee of either $\$ 5$ or $\$ 10$ for their participation, depending on the session and their role in the experimental economy. Additional earnings from their activity in the economies described below ranged from $\$ 11.56$ to $\$ 47.26$.
} 
Each session had several horizons, each with a variable number of periods. The number of periods in each horizon were determined by rolling a ten-sided die, after each period. If the die came up 1 or 2 , the horizon ended and all capital disappeared. If the die came up 3-10, the horizon continued. The number of horizons in different sessions ranged from 2 to 8 (see Table 3). In theory, if agents are risk-neutral, then a random ending should induce behavior which is theoretically equivalent to an infinite time horizon with discounting (as in the section 2.1, i.e., theory). The random ending appears to work adequately in other experimental domains. ${ }^{17}$

Each session was scheduled for a three-hour time interval. The instructions indicated that if the current horizon ended with more than 30 minutes remaining in the three-hour interval, a new horizon would be started with the same initial endowments of 5 units of capital and 10,000 Yen per person. Since initial endowments for each new horizon were independent of any activity in prior horizons, restarting after an exogenous random ending does not distort optimal decisions. Subjects were informed that if a horizon did not terminate by the end of the third hour of a session, it would continue on another evening. ${ }^{18}$ Out of 21 sessions, none actually had to be continue on another day.

\subsubsection{Timing within a period}

The sequences of activities within each period, in each of the four treatments, is shown in Figures $2 \mathrm{a}-2 \mathrm{~d}$. In all treatments, each period consisted of two decision stages: Trading in a market for output (stage 1), and either a private or a voting procedure to determine consumption (stage 2). We will now describe the timing in the baseline treatment as depicted in Figure 2a.

\footnotetext{
${ }^{17}$ Under the assumption that agents in the experiment are risk neutral in their final monetary payment, a constant probability of $20 \%$ of the horizon ending in each period is equivalent to an infinite horizon in which $\rho=0.25$. Other authors have used a similar rule to create the incentives of infinite horizon models in the laboratory. See for example Camerer and Weigelt (1993), Noussair and Matheny (2000), and Lei and Noussair (2002, 2003).

${ }^{18}$ Subjects were told that they would be free to return for that session and continue in their same roles at the point at which they left off. If a subject was unwilling or unable to return, a substitute would be recruited to replace him. The horizon earnings of the substitute would be awarded to the original subject as well as to the substitute himself. This technique preserves the incentive for subjects to behave as if they were to participate until the end of the horizon.
} 
In the baseline treatment, the timing of events within a period were as follows: At the beginning of period $t$, production occurred automatically as the computer program mapped $k_{t}^{i}$, the capital stock that each individual held, into output $\left(c_{t}^{i}+k_{t+1}{ }^{i}\right)$, according to the individual's production function $f^{i}\left(k_{t}^{i}\right)$. Subjects then participated in a market for output (stage 1). Each agent received an endowment of cash (10,000 currency units) to buy and sell output. The cash was convertible to dollar earnings at a conversion rate that was privately known to each subject in advance, so the cash had intrinsic value. Since the agents' utility and production functions were different, there were gains from trade in the exchange of output.

Output was traded in a "call market". ${ }^{19}$ Agents submitted demand curves specifying a sequence of (weakly) declining integer limit prices for each unit of capital that they wished to buy. ${ }^{20}$ An aggregate demand curve was then constructed from the individual curves in the usual way. The aggregate supply curve was vertical - the total amount of output available in the economy for the current period, $K_{t}$. The market-clearing price, $\mathrm{P}_{\mathrm{t}}$ was the lowest accepted bid - the $K_{t}$-th highest bid among all players, which is also the intersection of aggregate demand and supply. A player's gross purchase of capital was the number of units he or she demanded at the price $\mathrm{P}_{t}$ or higher (with ties at the price $\mathrm{P}_{\mathrm{t}}$ broken randomly). The net purchase of capital was the gross purchase minus the pre-trade holding. After the market was called, each agent either (a) paid $\mathrm{P}_{t}$ for each net unit he purchased, or (b) received $\mathrm{P}_{\mathrm{t}}$ for each net unit he sold. ${ }^{21}$

In stage 2, agents chose how much of the output to consume. In the baseline treatment, after market transactions were made, agents chose how much of their new posttrade output to allocate to consumption $c_{t}^{i}$. Before making their decisions, agents could use a

\footnotetext{
${ }^{19}$ Call markets do not converge as rapidly as double auctions, but they are fast to execute and enable many units to trade rapidly, which is an important property in an environment where there can be a large number of units of output in the optimal equilibrium. Furthermore, our baseline results replicate Lei and Noussair's (2003) identical economy which used double auctions, suggesting a robustness of basic findings across output-trading institutions.

${ }^{20}$ Agents submitted at least one price for each unit they held. For example, an agent with 14 units had to submit at least 14 positive prices. This guaranteed that the aggregate demand curve did not result in a zero price.

${ }^{21}$ In formal notation, the market reallocated output in the following manner. In period $t$ each agent $i$ submitted a demand curve $d_{i}^{t}(p)$, where $p$ was the price for output. An algorithm then calculated $\Sigma_{i} d_{i}^{t}(p)$, and solved for the price $p^{*}$ at which $\Sigma_{i} d_{i}^{t}\left(p^{*}\right)=\Sigma_{i} f_{i}\left(k_{i}^{t}\right)$. Agent $i$ 's final allocation of output was equal to $d_{i}^{t}\left(p^{*}\right)$. The net change in his holding of output was equal to $d_{i}^{t}\left(p^{*}\right)-f_{i}\left(k_{i}^{t}\right)$. Each agent $i$ received a cash transfer of $p^{*}\left[f_{i}\left(k_{i}^{t}\right)-d_{i}^{t}\left(p^{*}\right)\right]$.
} 
simulator which allowed them to study, by submitting hypothetical consumption and investment scenarios, how their choice of $c_{t}{ }^{i}$ affected their utility of consumption $u_{i}\left(c_{t}{ }^{i}\right)$, their remaining capital stock $k_{t+l}{ }^{i}$, and the quantity of output they would have at the beginning of the next period $f^{i}\left(k_{t+l}{ }^{i}\right)$. If the horizon continued (with probability 0.8 ), the unconsumed output of each individual automatically became $k_{t+l}{ }^{i}$. At the beginning of period $t+1$, production occurred as $k_{t+1}^{i}$ was mapped into output $\left(c_{t+1}{ }^{i}+k_{t+2}{ }^{i}\right)$, according to the function $f^{i}\left(k_{t+1}{ }^{i}\right)$, for all $i$, and the sequence repeated itself.

The sequence of events in the communication treatment (Figure 2b) was identical to the baseline treatment, except that agents were allowed to communicate with each other before the call market opened. Each agent's screen displayed a chat-room, which could be used to send and receive messages in real time for up to three minutes. Communication was unrestricted and all agents could read all messages.

The sequence of events in the voting treatment (Figure 2c) was identical to the baseline treatment until stage 2 . In stage 2 , consumption was not determined privately by individual agents as in the baseline treatment. Instead, two agents were randomly chosen ${ }^{22}$ in each period and told the amount of output currently held by each agent after the output market had closed. (Note that the proposers did not know other agents' utility or production functions, which remained private at all times.) Proposers then submitted proposals specifying how many units each agent in the economy would consume in that period. A proposal was a five-element vector of consumption levels, one element corresponding to each agent. The two proposals appeared simultaneously on all agents' computer screens. All agents were then required to vote for exactly one of the two proposals. The proposal that got the majority of the five total votes was immediately enacted, and each agent consumed the amount specified in the winning proposal.

The first stage of the hybrid treatment (Figure 2d) was identical to stage 1 of the communication treatment. Stage 2 was identical to that of the voting treatment. Keep in mind

\footnotetext{
22 Endogenizing which agents made proposals, and "campaigning," are obvious next steps. Because the experiments are already rather complex, we elected to begin with the simplest "anybody can grow up to be President" design. It also provides a benchmark sample of random-proposer sessions against which endogeneous-proposer designs can later be compared.
} 
that in the hybrid treatment, communication takes place before proposals are made and voted upon.

[Figures 2a-2d: About here]

\subsubsection{Initial Endowments and Agent Incentives}

Each of the five agents got an initial endowment of five units of capital, so the aggregate initial capital was $K_{0}=25$. The initial endowments were chosen so that the poverty trap outcome was likely to occur (based on earlier results of Lei and Noussair, 2003) in the baseline condition. This design choice permits us to see whether institutions can get economies out of the poverty trap.

Player $i$ 's period t earnings, in terms of experimental currency, were given by $u_{i}\left(c_{i}{ }^{t}\right)+$ $m_{i l}{ }^{t}-m_{i 0}{ }^{t}$, where $u_{i}\left(c_{i}{ }^{t}\right)$ denotes $i$ 's earnings from consumption, and $m_{i 0}{ }^{t}$ and $m_{i l}{ }^{t}$ denote $i$ 's cash holdings at the beginning and the end of period $t$, respectively. Over each horizon, individual $i$ 's earnings, were given by $\Sigma_{t}\left[u_{i}\left(c_{i}{ }^{t}\right)+m_{i l}{ }^{t}-m_{i 0}{ }^{t}\right]$, the total earnings in all of the periods $t$ making up the horizon. Because there was always an $80 \%$ chance the horizon would continue, each individual had an incentive to hold some output in the form of investment to allow consumption or sales in future periods in the horizon. An agent also had an incentive to sell output if the price was high, in order to increase his end of period cash holdings, as well as an incentive to purchase output at low prices in order to consume, produce more output in future periods, or resell in future periods at a higher price. Over an entire experimental session, participant $i$ 's dollar earnings were equal to $\tau_{i}+\gamma_{\mathrm{i}}\left(\Sigma_{j} \Sigma_{t}\left[u_{i}\left(c_{i}{ }^{t}\right)+m_{i l}{ }^{t}-m_{i 0}{ }^{t}\right]\right)$. Subscript $j$ indexes the horizon within an experimental session, $t$ is the period within a horizon, $\gamma_{\mathrm{i}}$ is agent $i$ 's conversion rate from experimental currency to US dollars, and $\tau_{i}$ is agent $i$ 's fixed participation fee. ${ }^{23}$

\subsection{Institutional Treatments and Possible Effects}

\footnotetext{
${ }^{23}$ The values of the fixed payments were $\$ 5$ for players 1 and 2 , and $\$ 10$ for players 3 , 4 , and 5 . The difference was to compensate players 3-5 for earnings in the experiment which were expected to be lower than for 1 and 2. In the baseline treatment, $\gamma_{\mathrm{i}}$ was 0.001 ( 1 Yen $=\gamma_{\mathrm{i}}$ US dollars for player $i$ ) for player 1 and 0.002 for players 2-5. In the other three treatments earnings were expected to be higher (and usually were), so the conversion rates were cut in half ( $\gamma_{\mathrm{i}}$ was 0.0005 for player 1 and 0.001 for players $2, \ldots, 5$ ).
} 
The four treatments in our experiment combine the absence or presence of communication and voting. The idea is to see whether communication and voting separately, and in combination, increase the likelihood that the economy avoids or escapes the poverty trap and reaches higher levels of output and welfare.

Note that equilibrium selection in our economies is a coordination problem that requires agents to conserve enough output, together, to push aggregate capital above the threshold. Communication is known to improve convergence to Pareto-dominant equilibria in normal form games (Camerer, 2003, Ch. 7). Communication could also interact with voting by enabling agents to talk about what kinds of consumption plans are best. In the field, the existence of institutions promoting communication between economic agents, such as free speech or a free press, has been statistically associated with higher rates of economic growth (Barro and Sala-i-Martin,1995; Barro, 1997).

In the voting treatments, the ability for an individual agent to commit all five agents to a winning proposal also provides a way to solve the coordination problem. For example, if one of the two agents selected to propose investment plans in each period acts like a benevolent social planner, and agents endorse her plan, then the steady-state optimum can be implemented in the voting treatment. In the field, democratic institutions are positively associated with higher rates of economic growth (see Barro and Sala-i-Martin, 1995). Our voting treatment enables the simplest possible training-wheels version of democratic politics - competition among proposals and automatic enforcement of an elected policy.

\section{Results}

The results section proceeds in six parts. First we present some basic comparisons across sessions and treatments. In subsection 3.2, we use a simple partial-adjustment model to forecast long-run results from the short-run data of each experimental session. Subsection 3.3 dissects different sources of inefficiencies in the entire economy (e.g., accumulating too little capital, versus allocating it inefficiently across agents). Subsection 3.4 looks at how economies manage to avoid the poverty trap, and how communication and voting work and interact. 


\subsection{Comparisons across sessions, and across treatments}

Figures $3-6$ show aggregate consumption behavior, $C_{t}$, in each session of the four treatments. Each chart illustrates the time series of $C_{t}$ for one session. Each Figure shows all the sessions from each treatment. The horizontal axes show the periods in a session. The dashed horizontal lines are the optimal equilibrium and the poverty trap levels of consumption, which are $C^{*}{ }_{H}=70$ and $C^{*}{ }_{L}=16$ units, respectively. The discontinuities in the time series represent the starts of new horizons. Consumption is highly correlated with welfare. Analogous data for aggregate capital stock $K_{t}$ across the four treatments are depicted in Figures 7 - 10.

[Figures 3-10: About Here]

Figure 3 shows that for the baseline treatment, the poverty trap is a powerful attractor. In four of five sessions, consumption (Figure 3) and total capital (Figure 7) remain close to the poverty trap level. Figure 7 shows that in one of these five sessions (Emory B3), the economy invests sufficiently in capital to surpass the threshold of 31 units in the first horizon, but it is unable to attain the threshold level of capital after that horizon ends, in the remainder of the session. In another session, Caltech B2, the capital stock surpasses the threshold in two different horizons, but in three horizons in between these two, the economy is in the poverty trap. These sessions show that avoiding the poverty trap in early periods or early horizons does not guarantee successful avoidance of poverty traps later. The fact that these baseline economies do not persistently exit the poverty trap replicates the results of Lei and Noussair (2003).

\subsection{Forecasts of long-run results and comparison across treatments}

Since the experimental sessions are constrained by the time in which agents can continuously participate, it is useful to have a rough extrapolation of what might happen if the sessions continued longer. The best available econometric tool is a statistical model that uses all the data from one session to forecast what would be likely to happen if that session 
continued indefinitely. Equation (4) is a specification, used previously ${ }^{24}$, which uses data from one session to forecast long-run behavior:

$$
Y_{j t}=B_{1} \frac{1}{t}+B_{2} \frac{t-1}{t}+\varepsilon_{j}+v_{j t}
$$

In this regression, $Y_{j t}$ is a dependent variable of interest, either the total utility $U\left(C_{t}\right)=$ $\sum_{i} u_{i}\left(c_{i}^{t}\right)$ actually realized in the economy, or the economy-wide capital stock $K_{t}=\sum_{i} k_{i}^{t}$, at time $t$. Period $t$ is the period number within a horizon, $j$ indexes the horizon within a session. $B_{1}$ and $B_{2}$ are the coefficients which are estimated from the data. The specification assumes that each horizon's dependent variable value is a period-weighted average of an initial condition value $\left(B_{1}\right.$, when period $\left.\mathrm{t}=1\right)$ and a long-run steady state value $B_{2}$ (the limiting value as $\mathrm{t} \rightarrow \infty)$. We call the estimate $B_{2}$ the convergence value of the dependent variable for the session. We will say that the dependent variable is converging to a particular level, such as an equilibrium prediction, if the convergence value $B_{2}$ is not significantly different from that predicted level. Since horizons within each session appear to be different (see Figures 3-10), we account for horizon-specific disturbances when estimating convergence levels by including a random-effects disturbance $\varepsilon_{j}$ for horizon $\mathrm{j}$.

Figure 11 plots the maximum likelihood estimates of the convergence values (i.e., estimates of $B_{2}$ ) for the dependent variables of total capital (x-axis) and total welfare (y-axis) of each of the 21 experimental sessions. Each circle corresponds to estimates from one session. The shaded lines through each point represent the width of $95 \%$ confidence intervals on each axis. The dotted lines represent the competitive equilibria. The intersection of the dotted lines in the lower left (bottom) indicates the poverty trap equilibrium; the intersection of the lines in the upper right (top) indicates the optimal equilibrium levels of consumption and welfare. Tables A-1 and A-2 in the Appendix contain the precise estimates of convergence values and standard errors. ${ }^{25}$

\footnotetext{
${ }^{24}$ Noussair et al. $(1995,1997)$ used this specification to estimate convergence of experimental international economies. Our analysis expands Noussair's by allowing different experimental sessions to have different steady-state levels, to explore reliability of convergence across experimental replications.

${ }^{25}$ In order to test the relevance of estimating the maximum-likelihood random-effect model, we compared our model to an OLS model using the Hausman specification test. The resulting chi-square statistic was significant at the 5 percent level for 19 out of 21 estimations, where each estimation corresponds to one session. This supports the hypothesis that the maximum-likelihood random-effect model is the better specification for equation (4).
} 
[Insert Figure 11: About here]

Since Figure 11 summarizes many important features of all 21 experimental sessions, we will work through it slowly, often referring back to the raw session-specific data as well. Figures 3 and 7 suggested that the baseline economies are unable to emerge persistently from the poverty trap equilibrium. The upper-left "baseline" graph in Figure 11 confirms this impression: All five of the 2-dimensional confidence intervals, extrapolating short-run results to the long-run, include the poverty trap levels for either capital or welfare (the intersection at the lower left of the Figure 11 graph). If the definition of "escaping a poverty trap" is that both the extrapolated capital and welfare levels must be significantly above the poverty-trap levels, then none of these economies has clearly escaped poverty. ${ }^{26}$ This finding replicates Lei and Noussair's (2003) results. The prevalence of poverty traps in the baseline treatment also sets the stage for a possible role of institutions in creating an escape from the poverty trap, toward the Pareto-optimal equilibrium.

In the communication treatment (Figures 4 and 8 show capital and welfare in each session, respectively), outcomes are more variable across sessions than in the baseline treatment. This is a reminder that economies which have an identical parametric structure, drawing participants randomly from the same population, can have different trajectories for reasons that are completely endogenous. Figure 4 shows that two of the communication sessions, Caltech C2 and Caltech C3, surpass the threshold level of capital and consumption moves toward the optimum. Two other sessions, Emory C3 and Caltech C1, remain near the poverty trap. The estimated convergence values of capital and welfare for the communication treatment, as shown in the lower-left graph in Figure 11 (and Tables A1-A2), confirm the long-run implication of the observations from the charts of Figures 4 and 8: Two sessions are

\footnotetext{
${ }^{26}$ Although session Caltech B2's estimated convergence value for capital is not statistically different from 45 (the optimal steady state level), its welfare convergence value is not statistically different from 5856 (the poverty trap). The same happens in session Emory $\mathrm{C} 1$ of the communication treatment. These examples show that an economy can escape poverty on one dimension but not necessarily another. While consumer welfare is the more important dimension (e.g., it determines, along with output-trading profits, how much agents actually earn), the capital measure is important too because an economy that has not significantly accumulated capital above the poverty-trap level is vulnerable to sinking back into poverty, as we see in sessions Emory B3 and Caltech B2.
} 
stuck in the poverty trap, two are close to the Pareto-optimal equilibrium, and two are imprecisely predicted to end up in between the two equilibria.

The voting treatment economies exhibit more variance within session (see Figures 5 and 9) than either the baseline or the communication treatments. The reason for an increase in the variance appears to lie in the centralized nature of decision making. In contrast to the baseline and communication treatments, where individual agents determine their consumption and investment choices in each period, in the voting treatment investment and consumption decisions are made by majority choice from only two alternative plans, which change each period. This results in large swings in economic activity from period to period. The estimated convergence values from the voting sessions, shown in the upper right graph of Figure 11, have wider confidence intervals, but only one session appears to be stuck in the poverty trap in the (estimated) long-run. In three of the five sessions, the estimated convergence level of capital (x-axis) includes the optimal steady-state value; at the same time, only one session statistically includes the optimal welfare level. This contradiction between the ability of voting to create optimal levels of total capital accumulation, but welfare significantly below the optimum is a result of the centralized way in which capital and consumption are simultaneously allocated among agents. Individual behavior in the voting treatment, which is considered in more detail in section 3.4, provides insights into why capital accumulation can be optimal while welfare lags behind.

The lower-right graph in Figure 11 shows that the hybrid treatment-communication and voting - is also variable (as shown by cross-session variability in Figures 6 and 10). However, Figure 11 shows that estimated convergence levels reliably escape the poverty trap in all five sessions. Two sessions, Emory $\mathrm{H} 1$ and Emory H2, attain welfare levels that are not significantly different from the optimal steady state.

Differences across the experimental conditions that appear to be evident in Figures 310 were also evaluated statistically using very conservative nonparametric rank-sum tests that treat each experimental session as one data point. We use the average value of total output and welfare across periods (to standardize sessions with different numbers of 
periods ${ }^{27}$ ). Table 4 shows the (one-tailed) p-values from Mann-Whitney rank-sum tests under the null hypothesis of no difference between treatments.

[Insert Table 4: About here]

Because there are only 5-6 data points in each treatment, there is only modest statistical power to detect differences across treatments. But even in this conservative test, we can reject equality of both output and welfare in the baseline versus voting, and baseline versus hybrid, comparisons. The test also rejects equality of welfare in the baseline versus voting and baseline versus hybrid treatments. Thus, voting appears to reliably improve capital and welfare statistically, and is often helped along by adding communication.

Now we briefly summarize our observations from the 21 sessions (before proceeding to look more closely at how communication and voting work):

The baseline sessions never fully escape the poverty trap. Communication and voting generally improve outcomes. In the hybrid treatment, the convergence values always escape the poverty trap. The strongest conclusion we can justify statistically is this: Simple institutions can reliably achieve good economic outcomes which never occur spontaneously without those institutions, and can always avoid bad outcomes which are common without those institutions.

As we describe later in section 3.4, communication in the hybrid treatment, improves both voter and proposer decisions. However, the voting process also distorts the economies by adding variance, which generally hurts capital-accumulation and welfare. Communication in the absence of voting usually clearly points to goals, but is not fully effective at coordinating capital-accumulation to exit the poverty trap. The next section measures the various kinds of efficiencies which can result.

\subsection{Sources of inefficiencies}

\footnotetext{
27 Weighting each horizon equally (which effectively gives larger weight to periods in short horizons than periods in long horizons) gives very similar results.
} 
Three types of allocative inefficiency can appear in these economies. The first inefficiency is an output gap, a lower actual production level than the highest possible production given the quantity of total capital in the economy. An output gap occurs in a period because the economy's capital at the end of the period is allocated among agents suboptimally (i.e., total output would go up if the agents who have the highest marginal products for capital swapped units with other agents who have lower marginal products). The output gap is $\left(F^{*}\left(\Sigma_{i} k_{i}^{t}\right)-\Sigma_{i} f^{o}\left(k_{i}^{t}\right)\right) / F^{*}\left(\Sigma_{i} k_{i}^{t}\right)$, where $F^{*}\left(\Sigma_{i} k_{i}^{t}\right)$ is the maximum possible production possible with total capital stock $\Sigma k_{i}^{t}$, and $\Sigma_{i} f^{o}\left(k_{i}^{t}\right)$ is the actual production. The output gap averages $39 \%, 32 \%, 34 \%$, and $28 \%$ in the baseline, voting, communication and hybrid treatments, respectively. The hybrid communication-voting rules allocate capital best, but the differences are small. Further experiments could explore the effect of institutions which are better-suited to allocating capital more productively across agents (e.g., more developed capital markets or industrial policies), especially when there is rapid technological change.

A second type of inefficiency is consumption inefficiency. The value of a given amount of aggregate consumption is maximized when the units are allocated to agents to equalize marginal utility of consumption. Consumption inefficiency is measured by the ratio $\left(U\left(C_{t}\right)-\Sigma v_{i}^{o}\left(c_{i}^{t}\right)\right) / U\left(C_{t}\right)$, where $\Sigma v_{i}^{o}\left(c_{i}^{t}\right)$ is the actual total value of consumption that agents achieve in period $t$, and $U\left(C_{t}\right)$ is the optimal level. This loss averages $4.9 \%, 6.2 \%, 6.4 \%$, and $8.6 \%$ in the baseline, voting, communication and hybrid treatments, respectively. These inefficiencies are low in all conditions because most economies converge to some equilibrium; so agents can discern the price of capital from the simple call market and consume optimally, which approximately equilibrates the marginal utility of consumption across agents (even though they have different utility functions).

The third type of inefficiency is dynamic inefficiency, which results from suboptimal allocations to investment and consumption given future incentives. Let $V\left(K_{t}\right)$ be the value of the economy's capital stock in period $t$, assuming that the economy behaves like a benevolent social planner, making optimal decisions from period $t$ onward. This value is an idealized benchmark which assumes the economy from period $t$ onward is directed by a benevolent social planner who chooses aggregate levels and individual allocations of capital and 
consumption to maximize total welfare. Given this hypothetical assumption, there is an optimal sequence of capital stock levels from period $t$ on. The market value of a unit of capital under this assumption can be calculated for each current level of capital stock. The market value in period $t$ is equal to the marginal utility of consumption in period $t$ along the economy's optimal trajectory. Let $V\left(K_{t}^{*}\right)$ be the value of the optimal quantity of capital stock given the current level of output and $V\left(K_{t}\right)$ be the value of the total level of capital generated from the individual agents' actual choices in period $t$ and assuming optimal decisions for the economy thereafter. The level of dynamic inefficiency in period $t$ is $\left(V\left(K_{t}^{*}\right)-V\left(K_{t}\right)\right) / V\left(K_{t}^{*}\right)$. This gap measures whether agents are making mistakes by consuming rather than investing for the future (as an idealized benevolent planner would).

This dynamic inefficiency measure shows the largest differences among treatments: $22 \%, 13 \%, 12 \%$, and $5 \%$, in the baseline, voting, communication and hybrid treatments, respectively. The hybrid treatment has the lowest dynamic inefficiency, which implies that both voting and communication are useful for trading off short-run consumption for long-run investment. $^{28}$

Finally, we explore whether the price of capital reflects sensible guesses about future consumption. Figures 12-15 show the time series of the market price for capital in each session of the four treatments. These prices can be compared to a rational expectations price, which is calculated for each unit of output by assuming the entire economy behaves optimally from the current period onward. This per-unit value is given by $V^{*}\left(K_{t}\right) / K_{t}$. The square-shaped markers in Figures 12-15 illustrate these rational-expectations predictions given the actual capital stock in each period $t$ for each session. The figures show that actual prices closely follow rational expectation predictions.

[Figures 12 -15: About here]

\subsection{How do the economies avoid the poverty trap?}

\footnotetext{
${ }^{28}$ The chat-room transcripts in both the communication and the hybrid sessions have no explicit attempts to reduce the output gap or consumption inefficiency.
} 
The call market for capital in these experiments appears to lead the economies to the vicinity of one equilibrium or the other, but does not reliably generate capital accumulation above the threshold unless it is supplemented with communication or voting. When both are present, in the hybrid treatment, the economy surpasses the threshold. This subsection explores the mechanisms which produce a threshold-crossing.

In the baseline treatment there were only three horizons in which the capital stock crossed the threshold of 31 (see Figure 7; Caltech B2, first and fifth horizons, and Emory B3, first horizon). In all three cases, one agent accumulated a large amount of capital by postponing consumption and bidding aggressively in the call market for capital, but the other four agents held small amounts. These single-handed efforts presumably were viewed as unprofitable and did not persist across consecutive horizons. The fact that these thresholdcrossings were created by individual action, and did not persist, indicates that specific mechanisms to coordinate behavior across all agents are necessary.

\subsubsection{The effect and content of communication}

The communication treatment sessions show that exchanging messages facilitates crossing the capital threshold in some horizons, but not in all of them (for example, in Emory $\mathrm{C} 3$ and Caltech $\mathrm{C} 1$ the economy never surpasses the threshold in any horizon). In general, when the threshold was surpassed for the first time in a session, it followed an exchange of messages in which one agent would suggest that players consume very little or nothing, and two or more players indicated agreement. The dialogue ${ }^{29}$ in horizon 3 of Emory C2 is a good example of this pattern:

Period 1:

(player 5)>NOBODY CONSUME

(player 1) $>$ DONT CONSUME

(player 4) $>$ lets get this show on the road...move quick

(player 5)>JUST THE FIRST ROUND, ITS WELL WORTH IT

(player 1) $>$ lose a lil...make a lot

(player 3) $>\mathrm{HOW}$

(player 2) $>$ by not consuming

\footnotetext{
${ }^{29}$ Reading the dialogue gives insight into how the subjects approach the experiment, in their own language. One session began with a subject saying, "Let's Enron this and make mad bread!".
} 
Period 2:

(player 1)>GOOD JOB

(player 4)>well done

(player 5)>THAT A WAY TO DO IT

In that session, four of the five agents endorse holding back consumption in the first period and they do cross the threshold. The subsequent period 2 messages are verbal high-fives.

Dialogue in horizon 2 of Emory $\mathrm{C} 1$ is another example, but with less initial agreement:

Period 1

(player 4) $>$ HOLD K for a round

(player 2)>once again...lets keep all our k...nobody consume this round

(player 4) $>$ is that good player 1 and 5

(player 1) $>$ we say that every round and no body does it

(player 5) $>$ we only have a few min. left

(player 4) $>$ just do it for the first round and we all will have a lot more to use

Period 2:

(player 4)>SEE!

(player 3)> good work

(player 2) $>$ wanna do it again?

(player 3)>let's let it keep growing

Notice that in period 1, after player 4 proposes to "HOLD K" and player 2 provides a seconding vote, player 1 is grumpy and skeptical. But a majority of players do hold capital and the aggregate capital crosses the threshold. In the next period, player 2 gloats, "SEE!" Player 3 (who said nothing in period 1) now chimes in and agrees. The economy then stayed above the threshold for the rest of the horizon and session.

To show whether these patterns are typical, Figure 16a displays the capital stock held at the end of each period on the y-axis; the threshold of 31 is the horizontal line. The numbers on the graph are the number of agents who either proposed to keep capital, or agreed with such a proposal, before each period. Periods in which the capital stock started below the threshold, then crossed it (or started above the threshold right away), usually coincided with a shift in the number of people agreeing with the proposal to keep capital, from a minority to a majority. For example, in Emory C2, in the second horizon, which lasted only one period, only one agent proposed to keep capital. In the third horizon (the $10^{\text {th }}$ period 
of the experiment), three people agreed and the capital stock crossed the threshold. When there was never a shift to a majority, the economy never got out of the trap (e.g., the agreement count numbers are only zero or one in Emory C3). But note that majority endorsement of capital accumulation seems to be necessary to cross the threshold, but not sufficient, because there are horizons with majority agreement in which capital accumulation did not result (e.g., Emory C1, horizon 1 and Caltech C1, horizons 1, 4, and 5). These exceptions show that being able to enforce verbal agreements through binding votes may add to nonbinding communication.

[Figure 16a: About here]

Formal analysis of the content of communication is messy but worth a brief and rough exploration. Comments can be divided into three categories likely to be relevant to economic performance: "Don’t consume”, “Keep K (general)", and "Specific proposal for investment". The first category consists of proposals suggesting zero consumption for all traders. The second category is a general statement that more capital should be held but does not propose specific actions. The third category includes specific suggestions such as "everyone hold on to 7", and "everyone try to keep 9-10". Table A-3 in the Appendix summarizes the content and timing of messages across sessions.

We use a random effects regression to estimate the effects of these comments on investment. The regression pools all sessions within a treatment and allows horizon-specific and session-specific disturbances. The dependent variable is the total number of units of capital $K_{t}$ allocated for investment in the economy in period t. The independent variables are dummy variables for the three categories of messages listed above (coded as 1 if that message was used at all, and 0 otherwise), and total output which is available to divide between consumption and capital $K_{t}$. Each session and each horizon is assumed to have a random effect.

Table 5 shows the results of the regressions for the communication and hybrid treatments (the hybrid results are discussed below). Under the communication treatment, vague general suggestions to hold capital do not significantly affect the levels of investment. 
However, specific proposals and the admonishment to not consume are significantly positively correlated with investment (i.e., the "specific proposal" and "don't consume" dummies are significant at the 10 and 5 percent levels, respectively).

[Table 5: About here]

A next step in studying communication is to further design experiments in which one or more agents are instructed to make comments which are correlated with avoidance of poverty traps. This would help us understand which types of messages reliably cause agents to achieve higher capital accumulation and better coordination.

\subsubsection{The effect and results of voting}

This subsection explores what agents proposed, and which of the two proposals each agent voted for, in the voting treatment. Each individual vote is a unit of observation. We include three variables that might correlate with voting. The first variable is "Higher consumption for the voter". This is a dummy variable which is 1 for the proposal that gives the agent higher consumption. This picks up purely short-run voting. The second variable is "Closer to the myopic optimum consumption." Myopic optimal consumption $\mathrm{c}^{\mathrm{m}}$ is defined as consumption which equalizes marginal utility of consumption with the expected future price of capital (assumed to be the current price). The "closer to" variable is a dummy which equals 1 for the proposal which is closest numerically to $\mathrm{c}^{\mathrm{m}}$. This variable picks up voting which is rational but also myopic, because it neglects the effect of lower consumption on surpassing the critical threshold. Finally, "More equal capital", is our third variable. This is a dummy variable which is 1 for the proposal that gives the most equal allocation of capital across agents. ${ }^{30}$ Equality of capital is inefficient (because agents have different utilities and productivity), but might be an expression of an egalitarian preference or a heuristic (and is also suggested in some communication transcripts).

\footnotetext{
${ }^{30}$ Equality is measured by the difference between the highest and the lowest levels of proposed investment for agents.
} 
The dependent variable is 1 when a subject votes for a proposal and 0 otherwise $\mathrm{e}^{31}$. Table 6 displays the results of a random-effects logit model, with horizon-specific and session-specific disturbances. The only feature of proposals which produces significant increases in voting for those proposals is "Higher consumption for the voter".

[Table 6: About here]

Summary statistics about which proposals were elected show mixed success. In both the voting and hybrid treatments, when both proposals forced total capital above the threshold of 31 , the one which "cleared the bar" by the least (i.e., minimizing the amount of capital above 31 or equivalently, maximizing consumption) was chosen in 17 of 18 cases. However, when the economy was below the capital threshold and exactly one of the two proposals forced total capital above the threshold (which also means less consumption), the threshold-crossing plan was only elected 12 times out of $21(57 \%){ }^{32}$ This success rate improved to 9 out of $11(82 \%)$ in the hybrid treatment where agents could talk about the proposals. Together, these data show that agents are naturally inclined to vote for plans with more consumption (and hence less investment); as a result, they do not always vote for the "fiscal austerity" plan that limits consumption in order to clear the capital-stock threshold. But communication helps, by allowing agents to talk each other into voting for the thresholdclearing plan.

While voting generally improved efficiency, there is also some evidence that determining investment purely by voting over proposals increased economic volatility: In each of the voting and hybrid treatments, there were two horizons in which the economy surpassed the threshold, then later fell below it, during the same horizon. This never happened in the treatments without voting.

The individual agents who made proposals showed a lot of rationality and restraint in how much consumption they proposed for themselves. Their proposed own-consumption is

\footnotetext{
${ }^{31}$ We excluded votes made by proposers, but including them does not alter the results much. Proposers do have a strong tendency to vote for their own proposals.

${ }^{32}$ The fact that the high-consumption, low-investment plan won $43 \%$ of the time is a simple experimental analogue of the difficulty many developing countries have in getting populations to accept fiscal austerity plans which impose short-run hardships but promise long-run development.
} 
above their myopic optimum only $25 \%$ of the time. ${ }^{33}$ Proposers also do not favor themselves over others: The consumption they propose for themselves is higher than for all of the other four agents only $22 \%$ of the time, and higher than the proposed group average only $48 \%$ of the time. (With no favoritism, the latter figures would be $20 \%$ and $50 \%$.) It appears that in this simple setting, either altruism or political competition between the two proposals is enough to restrain the proposers' self-interest. This could be studied further by restricting competition-e.g., a dictator makes a single proposal, or after a proposal is elected the winning proposer becomes an incumbent with no competition for several periods.

\subsubsection{Interactions of communication and voting in hybrid periods}

In the hybrid treatment with voting, communication did not follow the same pattern as in the communication-only treatment. In only 6 of 15 instances in which the threshold was surpassed was there majority agreement to increase the capital stock during the pre-voting communication. Figure $16 \mathrm{~b}$ shows the time series of capital stock and the number of agents who proposed or agreed to keep capital. An increase in that number does not appear to be necessary to cross the threshold, as it does in Figure 16a (the communication-only sessions). The voting process therefore appears to be a substitute for communication in coordinating a collective threshold-crossing decision. When there is voting on proposals, agreement is not needed because a single enforceable proposal can do the job of verbal agreement. This substitution effect is also manifested in the regression of capital stock on the content of messages, shown in Table 5: In the hybrid case, none of the message dummy variables that were correlated with capital stock in the communication-only treatments are significant (two even have the wrong sign).

In fact, in the hybrid treatment messages sometimes expressed a desire to consume a larger quantity (like special interest groups lobbying before an election), rather than calling for restrained consumption. This message was never sent in the no-voting treatments because agents could consume as much as they wanted.

Communication also substantially raised the number of proposals which planned to cross the capital-stock threshold in the right direction. When the economy was above the

\footnotetext{
${ }^{33}$ All the statistics reported in this paragraph are almost identical in voting and hybrid sessions.
} 
threshold in the previous period, $33 \%$ of the voting-only proposals would pull capital below the threshold, compared to only $17 \%$ in the hybrid case. When the economy was below the threshold in the previous period, only $36 \%$ of the voting-only proposals would push capital above the threshold, compared to $69 \%$ in the hybrid case. Pre-proposal communication is therefore very helpful in generating more proposals that create transitions in the right direction across the total capital threshold, and avoid transitions in the wrong direction.

Communication also appears to constrain selfish proposer decisions that harm everyone. Without communication, $8.3 \%$ of all proposals (18 in total) proposed a plan in which the proposer would consume more than his or her myopic optimum, and total capital would end up below the threshold. These proposals impose a big drain on the economy (including the proposer's own future consumption). Such proposals were much more rare (3 cases, $2 \%$ of the total) in economies with voting and communication.

[Figure 16b: About here]

\section{Conclusion}

This paper reports exploratory experiments on economic growth, and the growthenhancing effects of institutions, in an environment with two equilibria - a poverty trap and a Pareto-superior equilibrium that results when total capital exceeds a threshold that boosts productivity. Experiments allow the actual behavior of the economy to be compared with the theoretically optimal path, because all of the theoretically-relevant variables are created and carefully controlled - except for human behavior, which is left up to the agents. Experiments like this are particularly useful when there are multiple equilibria, because theory gives little guidance about which equilibria are likely to emerge. Such experiments also enable us to study effects of exogenously-created institutions and create hybrid mixtures of institutions to break multicollinearity.

The baseline economies tend to reliably converge to the poverty trap (replicating earlier results with a different market for trading output). This result shows that a market for output can lead to a competitive equilibrium, but the equilibrium that results is not typically Pareto-efficient. We can then see whether additional institutions help. 
We focus on the simplest possible incarnations of two types of political economy institutions - free expression, in the form of "chat room" communication before investment occurs, democratic majority-rule voting on binding proposals for how output is divided between consumption and investment, and a hybrid combination of communication and voting. Communication and voting both raise output and welfare over the baseline level. The combination of communication and voting does best of all. Extrapolating econometrically from each experimental session suggests that the baseline economies will never escape the poverty trap, and the hybrid (communication plus voting) economies will always escape the poverty trap. So institutions help. Why?

In sessions with communication, regressions show that the capital stock is raised by specific messages about what to do, and pleas to consume less. Crossing the productivity threshold, at the critical capital stock of 31 , seems to require one agent proposing to restrict consumption, and two more agents agreeing with this nonbinding proposal. This kind of de facto voting is necessary to push capital above the threshold, but is not sufficient.

Voting is a little more effective than communication because proposals are binding. Voting also seems to mute the effects of communication on coordinating activity, because good proposals are a substitute for trying to coordinate investment simply through messages. Competition over proposals that are voted upon also seems to restrain self-interest, because most proposers don't propose that they themselves consume too much (compared to a myopic optimum), and they rarely propose consuming more than other agents. Agents usually vote for a proposal which pushes total capital over the productivity threshold, but not always. Voting also creates a little more volatility, because the capital stock sometimes goes above the critical threshold, then dips below it, within a single experimental horizon (this never happens when there is no voting).

Adding communication generally interacts positively with voting because it produces more proposals that cross the critical capital-stock threshold, and more of those proposals actually are elected. Communication also restrains proposers further from proposing bad consumption plans in which they consume more than is optimal and create a capital stock below the critical threshold. 
These inferences are obviously specific to this modest sample of economies with special structure, which implements key features of a standard theoretical model with the added twist of a productivity threshold that creates multiple equilibria. There are many directions for future research. The experimental design can easily be expanded to include many other features of interest to growth economists, such as the possibility of endogenous growth (e.g., investments in technology with increasing returns, beyond the critical-threshold externality included here), multiple sectors with linkages, incomplete property rights, unequal wealth and income distribution, multiple economies with trade and immigration, and more fiscal, monetary, or regulatory policy options, such as taxation and redistribution. Different political systems such as dictatorship, indirect democracy, socialism, and anarchy can also be compared. In addition, in the lab, the study of institutions is not restricted to ones that naturally occur. We can create unnatural hybrids, like free expression and voting over dictatorship (single-proposer systems) to see what happens.

Institutions that are successful at producing wealth in one environment can be unpacked, and implemented in a different environment to test their robustness. Many questions spring to mind. Voting seems to work well here to restrain the proposers' selfinterest, but is this due to competition between two proposers, to fear of verbal sanctions, or to proposer altruism? Voting also generates more volatility, with economies slipping below the productivity threshold within a common horizon; can including more proposers or different voting systems dampen this volatility? If certain kinds of messages facilitate growth, can we cause growth reliably by having some agents transmit these messages? Answers to questions like these are within our grasp with more experiments of this type, as theories and field observations suggest conjectures we can explore experimentally. 


\section{References}

Acemoglu, Daron, Simon Johnson and James Robinson. "The Colonial Origins of Comparative Development: An Empirical Investigation," American Economic Review, December 2001, 91(5), 1369-1401.

Alesina, Alberto and Roberto Perotti. "The Political Economy of Growth: A Critical Survey of the Relevant Literature," World Bank Economic Review, September 1994, 8(3), 351371.

Alesina, Alberto and Dani Rodrik. "Distributive Politics and Economic Growth," Quarterly Journal of Economics, May 1994, 109(2): 465-490.

Angrist, Josh, Eric Bettinger, Erik Bloom, Elizabeth King, and Michael Kremer. "Vouchers for Private Schooling in Colombia: Evidence from a Randomized Natural Experiment," American Economic Review, December 2002, 92(5), 1535-1558.

Ashraf, Nava, Dean Karlan, and Wesley Yin. 2004. "Tying Odysseus to the Mast: Evidence from Commitment Savings Products in the Philippines," Harvard working paper http://www.people.fas.harvard.edu/ ashraf/SEED.pdf

Azariadis, Costas and Allan Drazen. "Threshold Externalities in Economic Development," Quarterly Journal of Economics, May 1990, 105(2), 501-26.

Azariadis, Costas, Intertemporal Macroeconomics, Cambridge, MA: Blackwell, 1993.

Banerjee, Abhijit, Dilip Mookherjee, Kaivan Munshim and Debraj Ray. "Inequality, Control Rights, and Rent Seeking: Sugar Cooperatives in Maharashtra," Journal of Political Economy, February 2001, 109(1), 138-90.

Barro, Robert J. and Xavier Sala-i-Martin. Economic Growth, New York: McGraw-Hill, 1995.

Barro, Robert J. Determinants of Economic Growth: A Cross-Country Empirical Study, Cambridge, MA: MIT Press, 1997.

Baumol, William J. "Productivity Growth, Convergence, and Welfare: What the Long-Run Data Show," American Economic Review, 76(5), December 1986, 1072-85.

Camerer, Colin and Keith Weigelt. "Convergence in Experimental Double Auctions for Stochastically Lived Assets," in D. Friedman and J. Rust, eds., The Double Auction Market: Institutions, Theories, and Evidence, New York: Addison-Wesley, 1993, 355-96.

Camerer, Colin. Behavioral Game Theory: Experiments in Strategic Interaction, Princeton, NJ: Princeton University Press, 2003.

Cardenas, Juan Camilo and Jeffrey Carpenter. 2004. "Experimental development economics: A review of the literature and ideas for future research," Working paper, Universidad de los Andes.

Cass, David. "Optimal Growth in an Aggregative Model of Capital Accumulation," Review of Economic Studies, July 1965, 32(3), 233-40.

Cooper, Russell. 2002. "Estimation and Identification of Structural Parameters in the Presence of Multiple Equilibria," Working paper, Boston University.

Duffy, John and Eric Fisher. 2004. "Sunspots in the laboratory," Working paper, University of Pittsburgh, http://www.pitt.edu/ jduffy/docs/sunspots0503.pdf

Durlauf, Steven and Danny Quah. "The New Empirics of Economic Growth," in John Taylor and Michael Woodford, eds., Handbook of Macroeconomics, Amsterdam, New York and Oxford: Elsevier Science, North-Holland, 1999, 235-308. 
Galor, Oded and Joseph Zeira. "Income Distribution and Macroeconomics," Review of Economic Studies, January 1993, 60(1), 35-52.

Islam, Nazrul. "What Have We Learned from the Convergence Debate? A Review of the Convergence Literature," Journal of Economic Surveys, July 2003, 17 (3), 309-362.

Knack, S., and P. Keefer. "Does Social Capital Have an Economic Payoff? A Cross-Country Investigation," Quarterly Journal of Economics, November 1997, 112(4), 1251-1288.

Koopmans, Tjalling C. "On the Concept of Optimal Economic Growth," in Pontifical Academy of Sciences, The Econometric Approach to Development Planning, Amsterdam: North-Holland, 1965, 255-87.

Lei, Vivian and Charles Noussair. "An Experimental Test of an Optimal Growth Model," American Economic Review, June 2002, 92(3), 549-570.

Lei, Vivian and Charles Noussair. 2003. "Equilibrium Selection in an Experimental Macroeconomy,” Working paper, Emory University.

Lucas, Robert E. Jr. "Adaptive Behavior and Economic Theory," Journal of Business, October 1986, 59(4), Part 2, S401-426.

Murphy, Kevin M., Andrei Shleifer, and Robert W. Vishny. "Industrialization and the Big Push," Quarterly Journal of Economics, May 1989, 106(2), 503-530.

Noussair, Charles N. and Kenneth Matheny. "An Experimental Study of Decisions in Dynamic Optimization Problems," Economic Theory, March 2000, 15(2), 389-419.

Noussair, Charles, Charles Plott, and Raymond Riezman. "An Experimental Investigation of the Patterns of International Trade," American Economic Review, June 1995, 85(3), 462-491.

. "The Principles of Exchange Rate Determination in an International Finance Experiment," Journal of Political Economy, August 1997, 105(4), 822-862.

Plott, Charles and Glen George. "Marshallian vs. Walrasian Stability in an Experimental Market," Economic Journal, May 1992, 102, 437-460.

Ramsey, Frank P. “A Mathematical Theory of Saving,” Economic Journal, December 1928, $38,543-559$.

Rosenstein-Rodan, Paul. "Problems of Industrialization of Eastern and Southeastern Europe," Economic Journal, June-September 1943, 53, 202-211.

Sachs, Jeffrey and Andrew Warner. "Economic Reform and the Process of Global Integration," Brookings Papers on Economic Activity, 1995:I, 1-118. . "The Curse of Natural Resources," European Economic Review, May 2001, 45(4-6), 827-838.

Smith, Vernon. "An Experimental Study of Competitive Market Behavior," Journal of Political Economy, June 1962, 70(3), 111-137.

Temple, Jonathan. "The New Growth Evidence," Journal of Economic Literature, March 1999, 37(1), 112-156. 
Table 1: Parameters of the model

\begin{tabular}{ll}
\hline$U\left(C_{t}\right)$ : economy-wide utility & $400 C_{t}-2 C_{t}^{2}$ \\
function & \\
$F\left(K_{t}\right):$ economy-wide production & $A K_{t}^{0.5}$ \\
function & $\underline{A}=7.88 ; \quad$ if $K_{t}<31$ \\
A: production-efficiency parameter & $\bar{A}=16.771 ;$ if $K_{t} \geq 31$ \\
$\hat{K}:$ threshold level of capital stock & 31 \\
$\rho:$ discount rate & 0.25 \\
$\delta:$ depreciation rate & 1 \\
\hline
\end{tabular}

Table 2: Values of variables in equilibrium

\begin{tabular}{|c|c|c|}
\hline Variable & $\begin{array}{l}\text { Optimal Steady } \\
\text { State }\end{array}$ & Poverty Trap \\
\hline Capital (K) & 45 & 9 \\
\hline Consumption (C) & 70 & 16 \\
\hline Price $(\mathrm{P})$ & 118 & 334 \\
\hline Welfare (U) & 18,060 & 5,856 \\
\hline
\end{tabular}


Table 3: Session information for all treatments

\begin{tabular}{|c|c|c|c|c|c|}
\hline Treatment & Date & $\begin{array}{c}\text { \# of } \\
\text { horizons }\end{array}$ & $\begin{array}{c}\text { \# of periods per } \\
\text { horizon, h: } \\
(\mathrm{h} 1, \mathrm{~h} 2, \mathrm{~h} 3, \ldots \mathrm{hi})\end{array}$ & $\begin{array}{l}\text { Avg. } \\
\text { earnings } \\
\text { in Yen }\end{array}$ & $\begin{array}{c}\text { Avg. } \\
\text { earnings } \\
\text { in } \$^{\S}\end{array}$ \\
\hline \multicolumn{6}{|l|}{ Baseline } \\
\hline Emory B1 & $03 / 22 / 04$ & 5 & $(4,7,2,2,7)$ & 25,343 & 39.24 \\
\hline Emory B2 & $03 / 24 / 04$ & 6 & $(3,3,7,2,1,4)$ & 23,801 & 36.84 \\
\hline Emory B3 & 04/07/04 & 6 & $(5,2,1,3,4,4)$ & 28,678 & 47.26 \\
\hline Caltech B1 & $07 / 08 / 04$ & 4 & $(4,4,7,6)$ & 22,274 & 34.80 \\
\hline Caltech B2 & $07 / 12 / 04$ & 6 & $(2,3,3,2,3,1)$ & 17,007 & 26.87 \\
\hline \multicolumn{6}{|c|}{ Communication } \\
\hline Emory $\mathrm{C} 1$ & $03 / 22 / 04$ & 2 & $(7,7)$ & 19,848 & 16.06 \\
\hline Emory C2 & $03 / 23 / 04$ & 5 & $(8,1,3,5,2)$ & 27,607 & 23.57 \\
\hline Emory C3 & $04 / 01 / 04$ & 4 & $(3,7,6,4)$ & 23,458 & 19.26 \\
\hline Caltech C1 & $07 / 15 / 04$ & 5 & $(6,1,1,2,4)$ & 14,219 & 11.56 \\
\hline Caltech C2 & 07/19/04 & 5 & $(3,4,1,3,6)$ & 33,060 & 28.64 \\
\hline Caltech C3 & $10 / 07 / 04$ & 4 & $(11,2,5,2)$ & 52,170 & 44.24 \\
\hline \multicolumn{6}{|l|}{ Voting } \\
\hline Emory V1 & $03 / 24 / 04$ & 4 & $(11,5,3,3)$ & 36,767 & 31.05 \\
\hline Emory V2 & $03 / 27 / 04$ & 6 & $(6,2,1,2,5,5)$ & 25,750 & 21.86 \\
\hline Emory V3 & $04 / 01 / 04$ & 5 & $(1,5,1,7,4)$ & 37,355 & 32.27 \\
\hline Caltech V1 & $07 / 13 / 04$ & 7 & $(6,2,4,2,1,3,5)$ & 35,963 & 30.85 \\
\hline Caltech V2 & $07 / 14 / 04$ & 8 & $(3,4,8,2,1,3,1,2)$ & 31,330 & 25.66 \\
\hline \multicolumn{6}{|l|}{ Hybrid } \\
\hline Emory H1 & $06 / 01 / 04$ & 2 & $(4,6)$ & 17,202 & 27.15 \\
\hline Emory H2 & 09/01/04 & 3 & $(8,2,4)$ & 23,102 & 18.74 \\
\hline Emory H3 & 09/01/04 & 4 & $(4,4,7,4)$ & 37,190 & 31.27 \\
\hline Caltech H1 & $08 / 03 / 04$ & 5 & $(5,8,2,2,2)$ & 48,015 & 42.66 \\
\hline Caltech H2 & 08/04/04 & 3 & $(2,9,2)$ & 22,045 & 18.72 \\
\hline
\end{tabular}

$\S=$ Conversion rates of experimental currency into US dollars differed depending on the treatment and player's role. See section 2.3.6. 
Table 4: P-values for rank sum tests of differences in output and welfare between treatments

\begin{tabular}{l|ccc}
\hline Output & Communication & Voting & Hybrid \\
\hline Baseline & 0.164 & 0.016 & 0.004 \\
Communication & & 0.214 & 0.214 \\
Voting & & & 0.155 \\
\hline Welfare & & Voting & Hybrid \\
\hline \multicolumn{1}{|c}{} & & 0.016 & 0.004 \\
Baseline & Communication & 0.214 & 0.123 \\
Communication & 0.214 & & 0.048 \\
Voting & & &
\end{tabular}

Note: P-values are for one-tailed rank sum tests. The alternative hypothesis is that values of output or welfare for the treatment listed in the column are larger than values for the treatment listed in the row. Therefore, a low p-value means the row treatment produces lower numbers than the column treatment.

Table 5: Random-effects GLS estimation of the Effect of Communication Content on Capital Stock Level

\begin{tabular}{|c|c|c|}
\hline Communication & $\mathrm{R}^{2}=0.86$ & \\
\hline & Estimated coefficient & Std Error $\mathrm{p}>|\mathrm{t}|$ \\
\hline Total available output & 0.46 & $0.02 \quad 0.00$ \\
\hline Don't Consume & 6.99 & 2.280 .00 \\
\hline Keep K (general) & 1.13 & 2.180 .61 \\
\hline Specific Proposal & 4.32 & 2.530 .09 \\
\hline Constant & 1.71 & $1.50 \quad 0.25$ \\
\hline Hybrid & $\mathrm{R}^{2}=0.54$ & \\
\hline & Estimated coefficient & Std Error $p>|t|$ \\
\hline Total availabl & 0.34 & 0.040 .00 \\
\hline Don't Consume & 8.02 & 7.040 .25 \\
\hline Keep K (general) & -5.12 & 3.370 .13 \\
\hline Specific Proposal & -5.95 & 4.460 .18 \\
\hline Constant & 14.87 & 3.960 .00 \\
\hline
\end{tabular}

Note: Dependent variable is economy-wide capital stock level. 
Table 6: Influences on voting decisions, random-effects logit estimation

\begin{tabular}{|c|c|c|c|}
\hline Voting Sessions & $\begin{array}{l}\text { Estimated } \\
\text { coefficient }\end{array}$ & Std Error & $\mathrm{p}>|\mathrm{t}|$ \\
\hline Higher own consumption & 0.68 & 0.24 & 0.05 \\
\hline $\begin{array}{l}\text { Higher total } \mathrm{K} \text { in the } \\
\text { economy }\end{array}$ & 0.81 & 0.24 & 0.73 \\
\hline $\begin{array}{l}\text { Closer to the myopic } \\
\text { optimum consumption }\end{array}$ & 0.01 & 0.02 & 0.75 \\
\hline Equal investment & 0.17 & 0.21 & 0.40 \\
\hline Constant & -0.96 & 0.31 & 0.00 \\
\hline \multicolumn{4}{|l|}{ Hybrid Sessions } \\
\hline Higher own consumption & 1.05 & 0.28 & 0.00 \\
\hline $\begin{array}{l}\text { Higher total } \mathrm{K} \text { in the } \\
\text { economy }\end{array}$ & 0.29 & 0.29 & 0.32 \\
\hline $\begin{array}{l}\text { Closer to the myopic } \\
\text { optimum consumption }\end{array}$ & -0.02 & 0.02 & 0.28 \\
\hline Equal investment & -0.27 & 0.28 & 0.33 \\
\hline Constant & -0.66 & 0.38 & 0.07 \\
\hline
\end{tabular}

Note: Dependent variable is 1 if agent votes for proposal, 0 otherwise. 
Figure 1: Aggregate Production and Demand Functions, discontinuous increase in input-output productivity when aggregate capital stock reaches 31 .
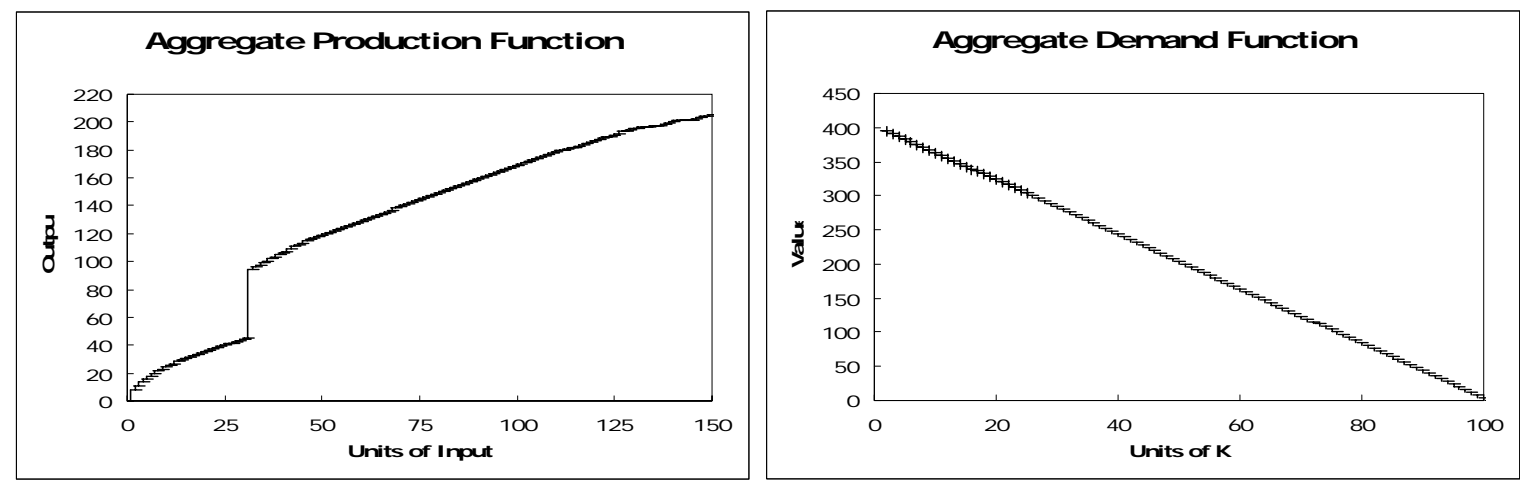


\section{Figures 2a-2d: Timing within a period}

\section{Baseline}

Period $\mathrm{t}$ begins
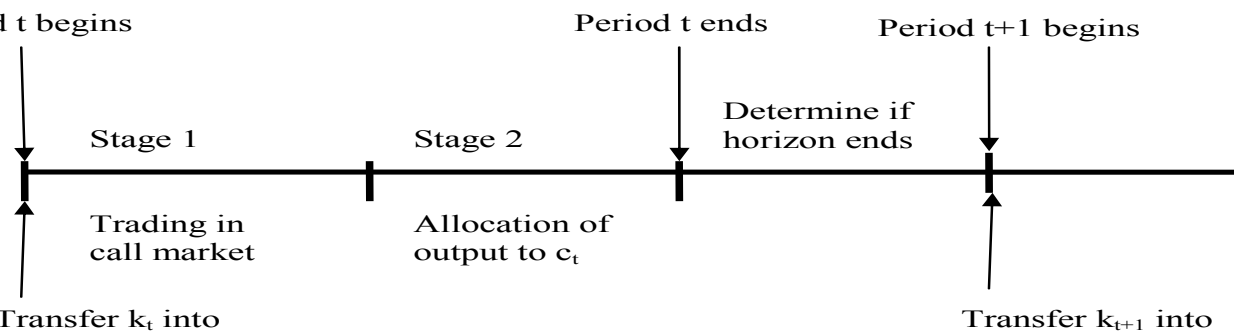

output $\left(c_{t}+k_{t+1}\right)$

Period $\mathrm{t}$ begins

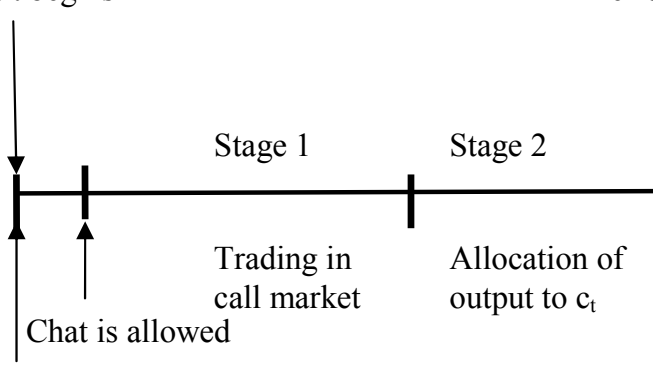

Transfer $\mathrm{k}_{\mathrm{t}}$ into output $\left(\mathrm{c}_{\mathrm{t}}+\mathrm{k}_{\mathrm{t}+1}\right)$

Period $\mathrm{t}$ begins

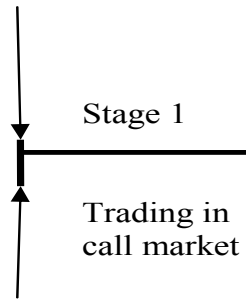

Transfer $\mathrm{k}_{\mathrm{t}}$ into output $\left(c_{t}+k_{t+1}\right)$

\section{Period $\mathrm{t}$ begins}

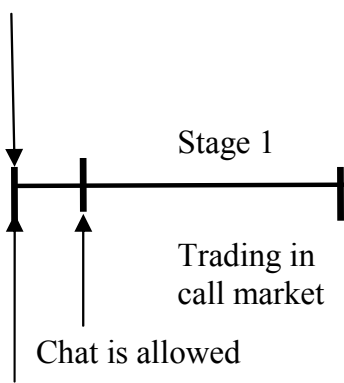

Transfer $\mathrm{k}_{\mathrm{t}}$ into output $\left(\mathrm{c}_{\mathrm{t}}+\mathrm{k}_{\mathrm{t}+1}\right)$

\section{Hybrid}

to $\mathrm{c}_{\mathrm{t}}$

\section{Communication}

Voting

Transfer $\mathrm{k}_{\mathrm{t}+1}$ into output $\left(\mathrm{c}_{\mathrm{t}+1}+\mathrm{k}_{\mathrm{t}+2}\right)$

Period $\mathrm{t}+1$ begins

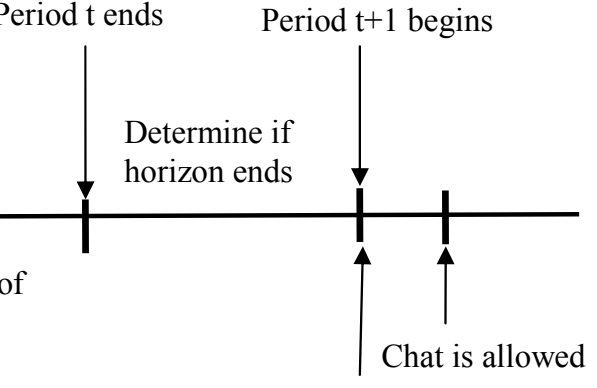

Transfer $\mathrm{k}_{\mathrm{t}+1}$ into output $\left(\mathrm{c}_{\mathrm{t}+1}+\mathrm{k}_{\mathrm{t}+2}\right)$

Period t ends
Period $\mathrm{t}+1$ begins

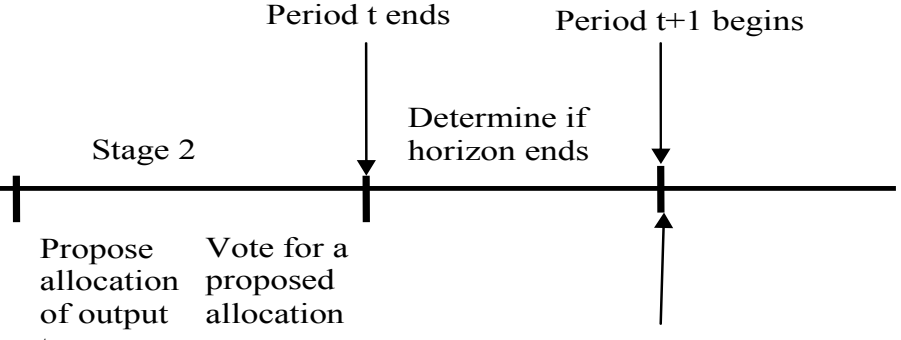

to $\mathrm{c}_{\mathrm{t}}$

Transfer $\mathrm{k}_{\mathrm{t}+1}$ into output $\left(\mathrm{c}_{\mathrm{t}+1}+\mathrm{k}_{\mathrm{t}+2}\right)$

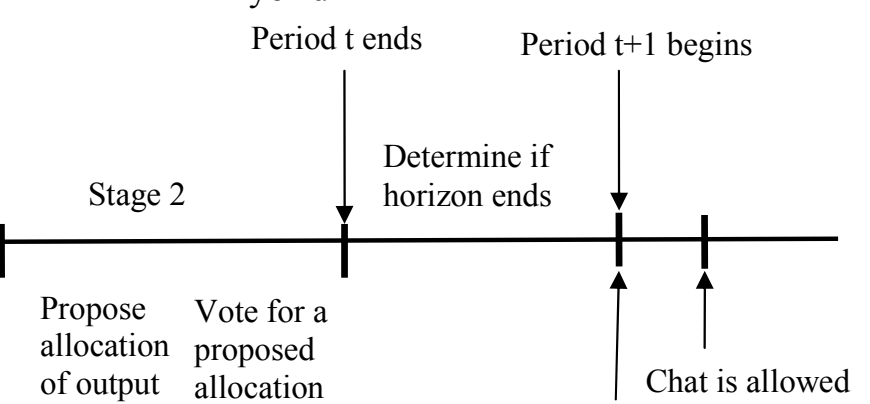

Transfer $\mathrm{k}_{\mathrm{t}+1}$ into output $\left(\mathrm{c}_{\mathrm{t}+1}+\mathrm{k}_{\mathrm{t}+2}\right)$ 
Figure 3: Observed and Equilibrium Aggregate Consumption, Baseline Treatment, $C^{*}$ optimal $=70, C^{*}$ inferior $=16^{\S}$
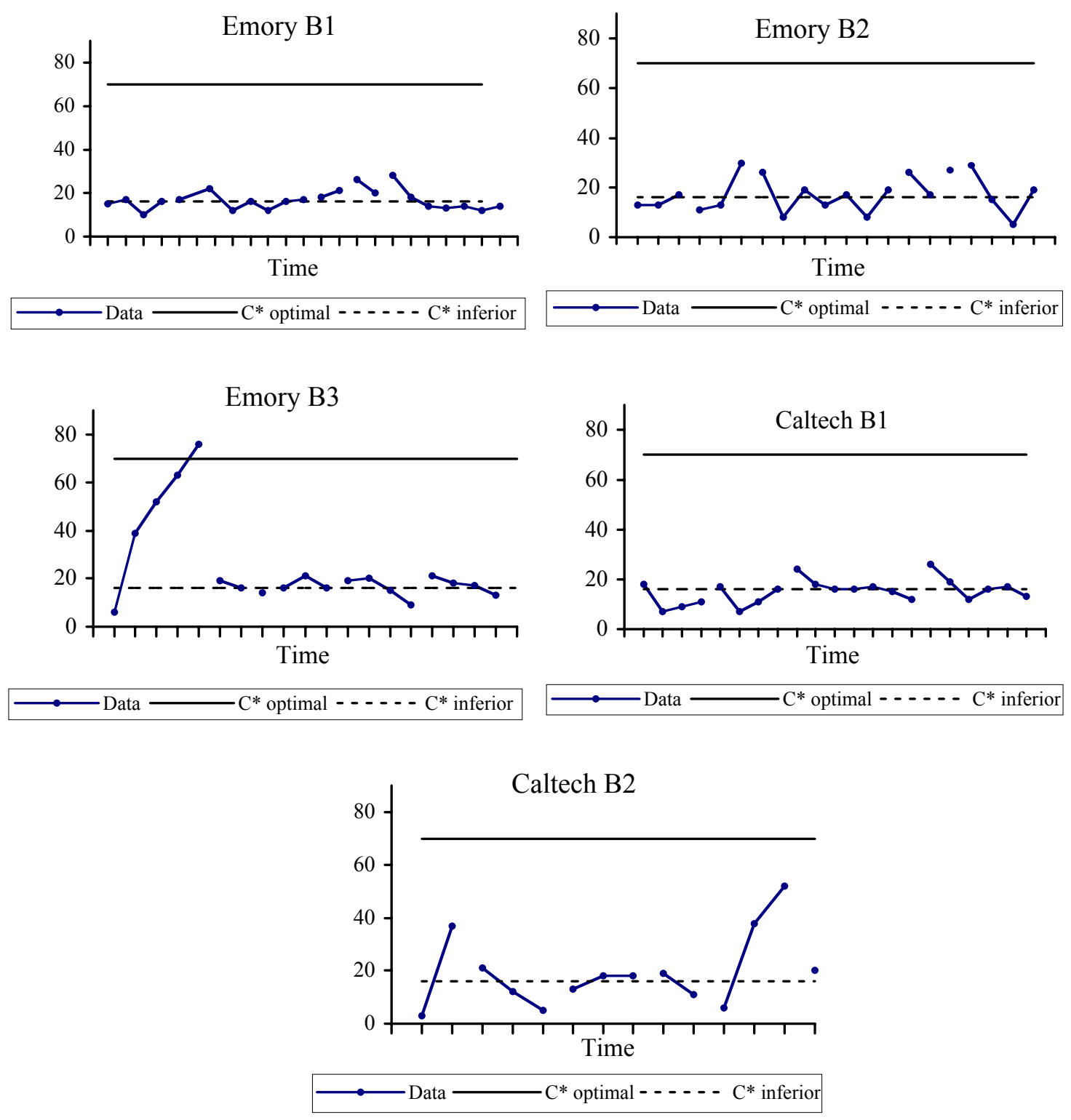

$\S=$ Each data point represents a period in a horizon. Horizons are separated by spaces. For instance, in Emory B1 the first horizon had four periods. 
Figure 4: Observed and Equilibrium Aggregate Consumption, Communication Treatment, $C^{*}$ optimal $=70, C^{*}$ inferior $=16$
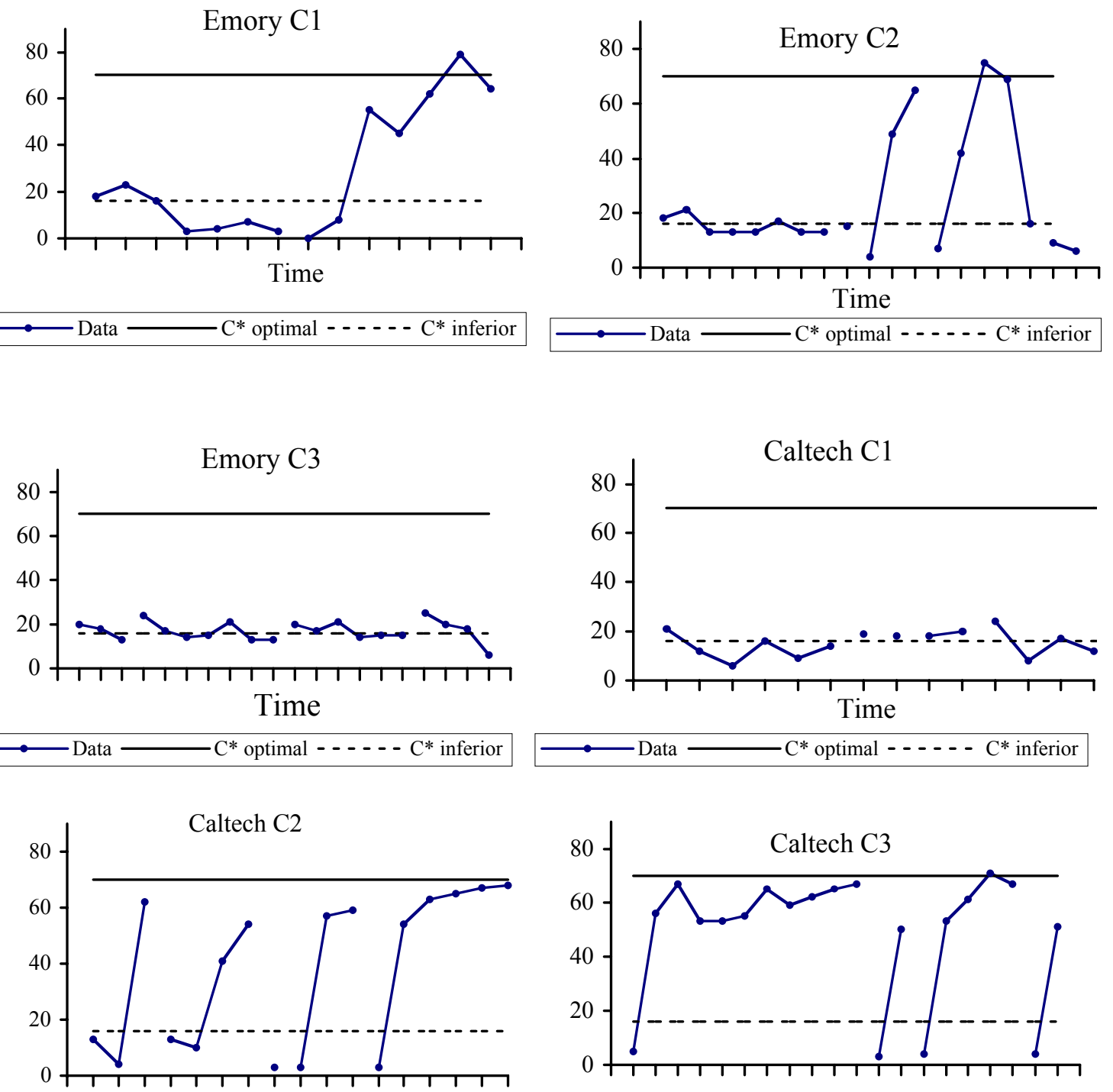

Time

Time

$\longrightarrow$ Data $\longrightarrow$ C* optimal - - - - - C* inferior

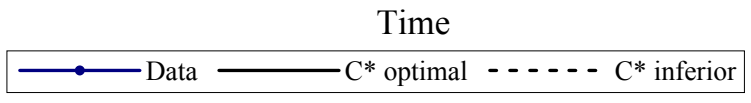


Figure 5: Observed and Equilibrium Aggregate Consumption, Voting Treatment, $C^{*}$ optimal $=70, C *$ inferior $=16$
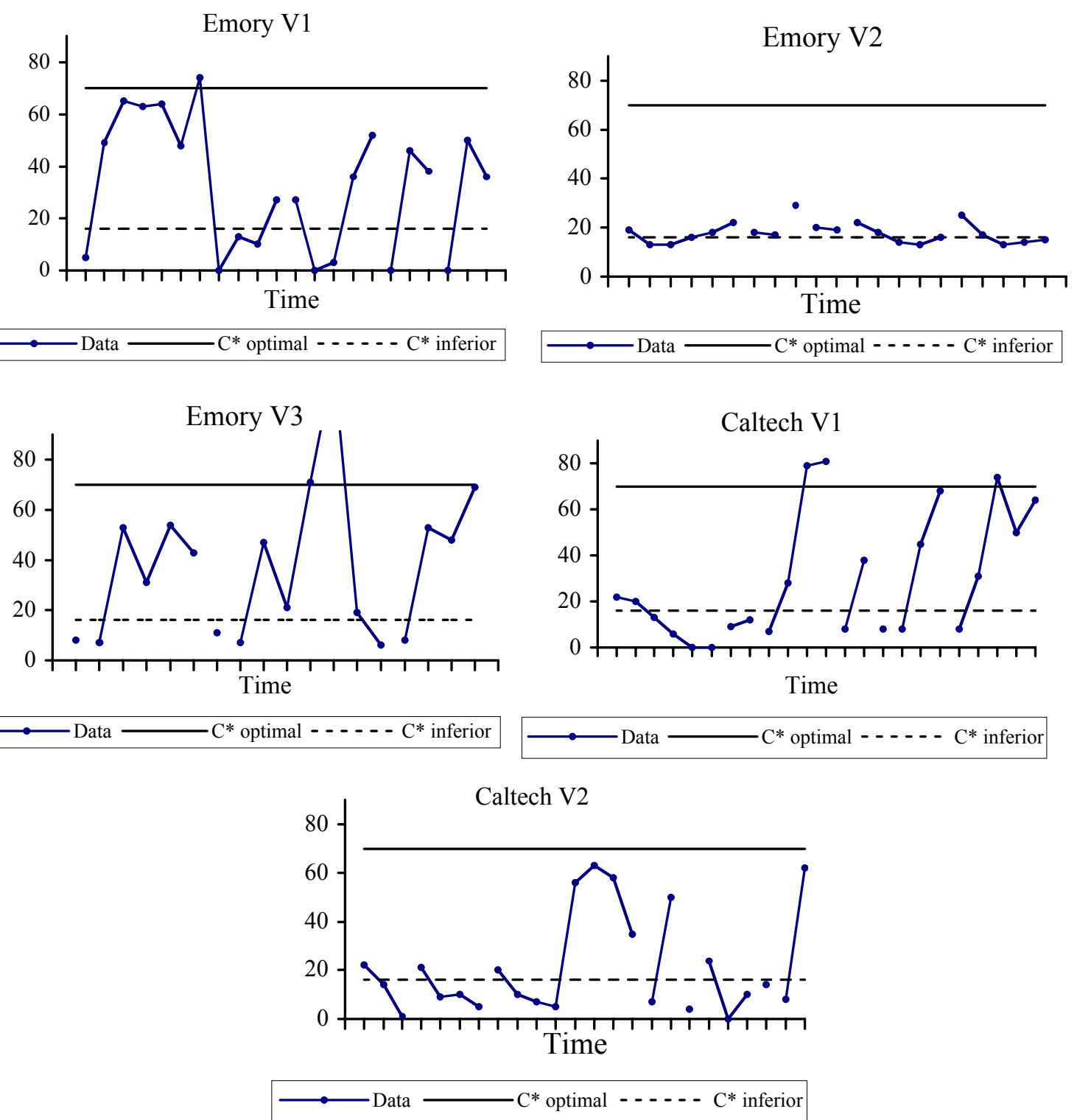
Figure 6: Observed and Equilibrium Aggregate Consumption, Hybrid Treatment, $\mathrm{C}^{*}$ optimal $=70, \mathrm{C}^{*}$ inferior $=16$
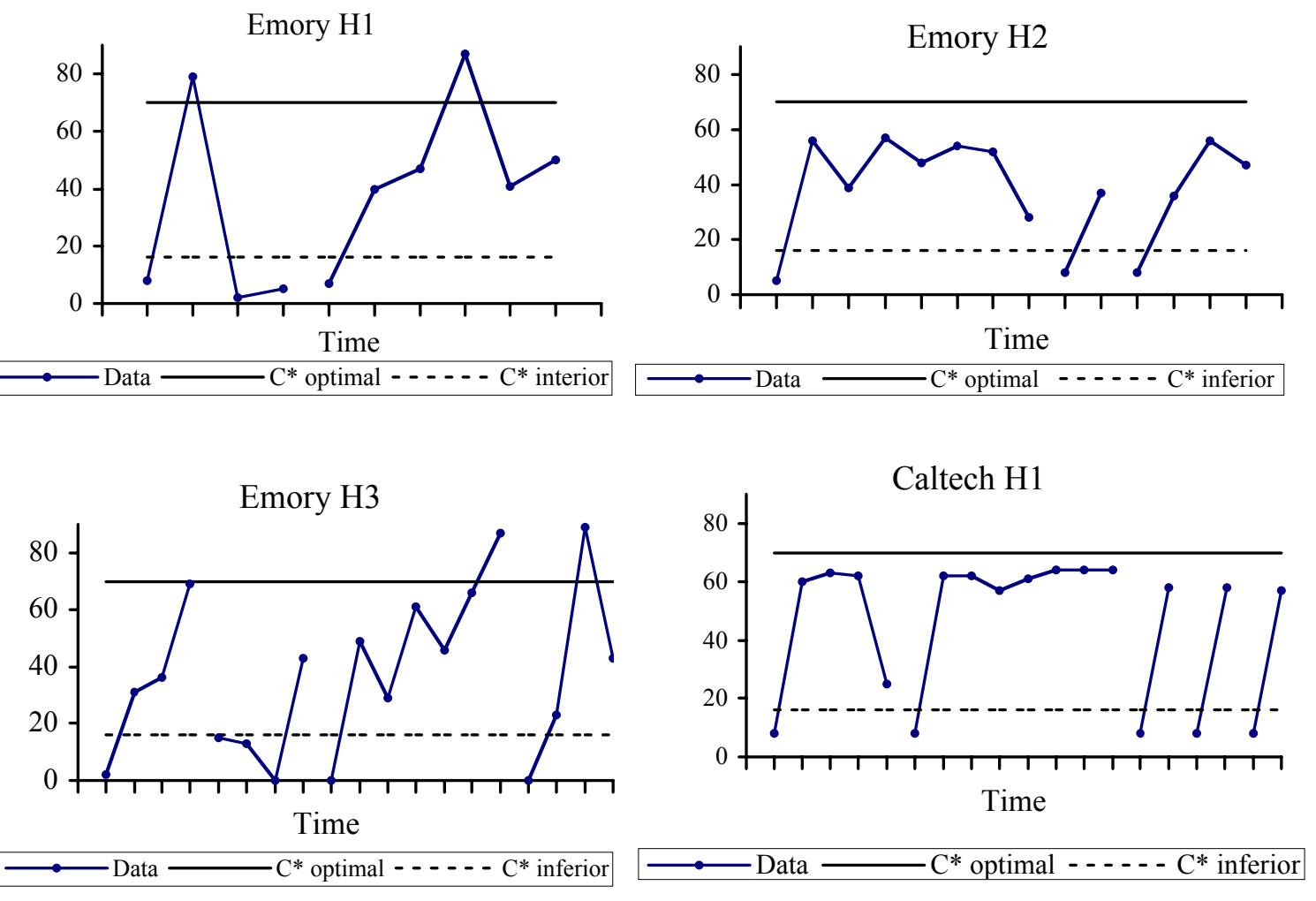

Caltech $\mathrm{H} 2$

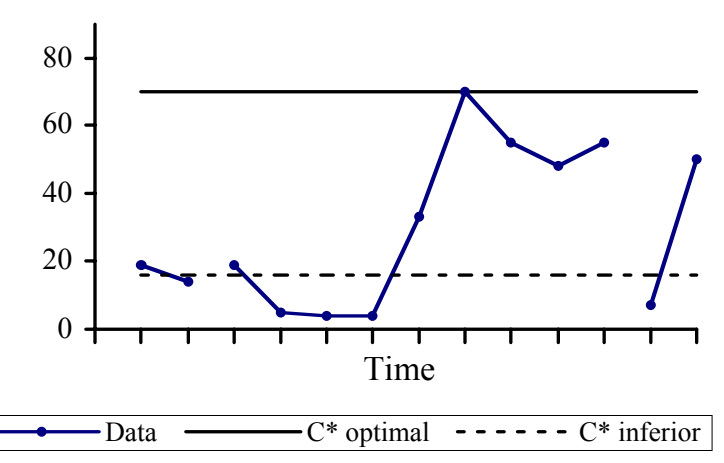


Figure 7: Observed and Threshold Level of Capital, Baseline Treatment, K threshold $=31$

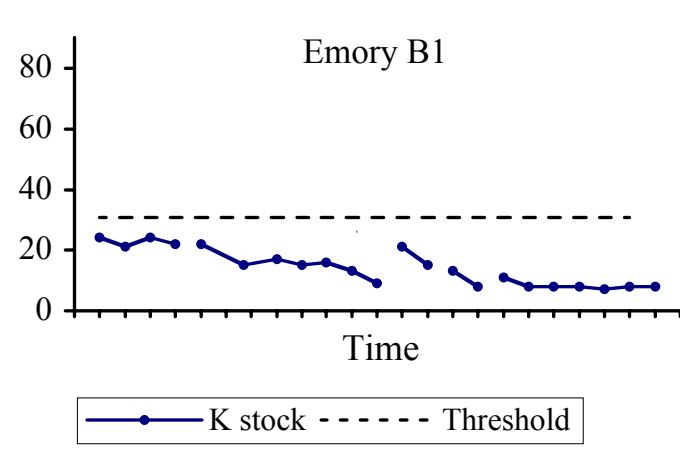

Emory B3

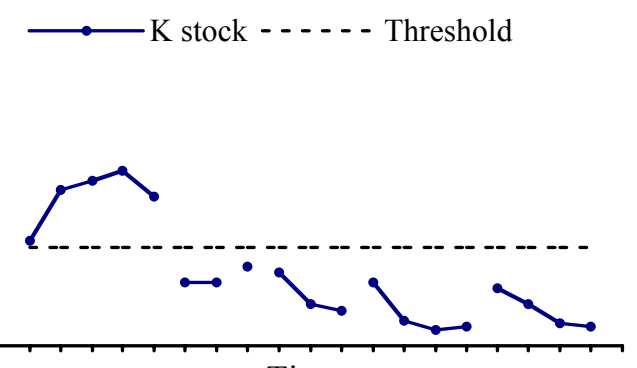

Time

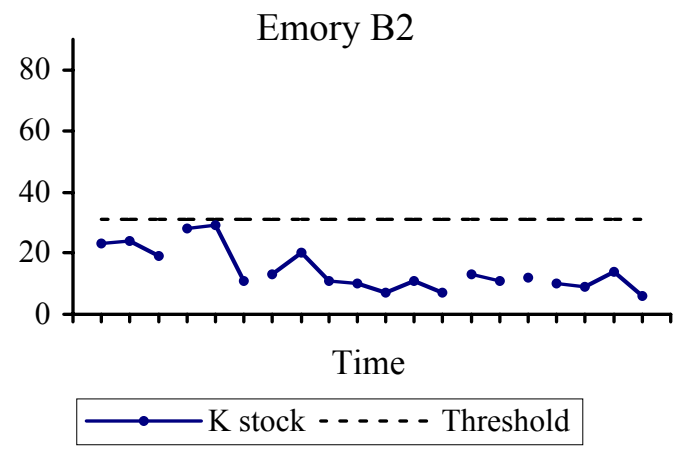

Caltech B1
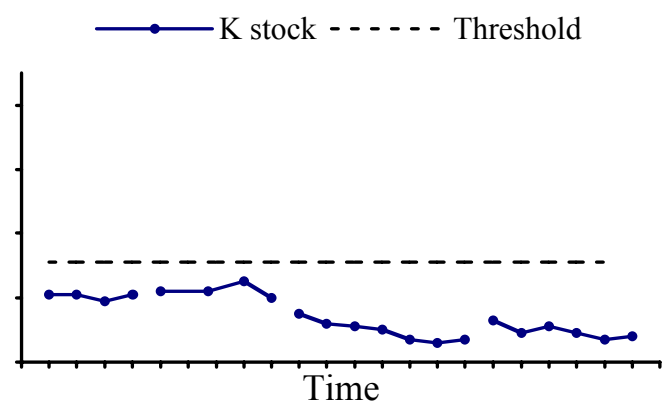

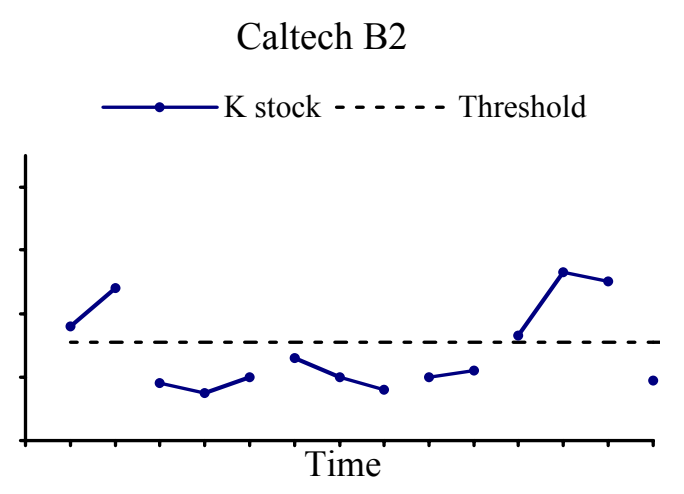


Figure 8: Observed and Threshold Level of Capital, Communication Treatment, K threshold $=31$
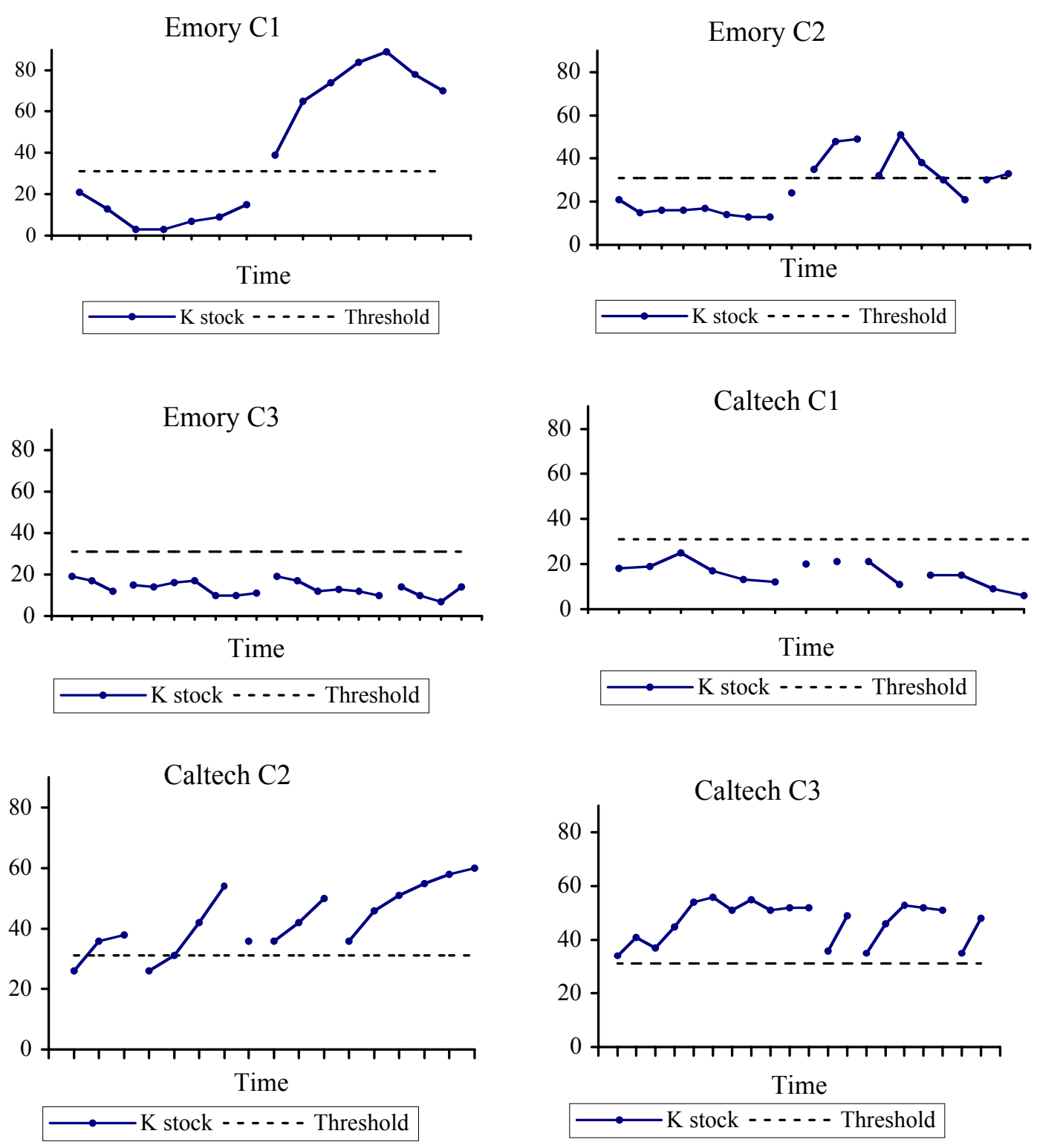
Figure 9: Observed and Threshold Level of Capital, Voting Treatment, K threshold $=31$
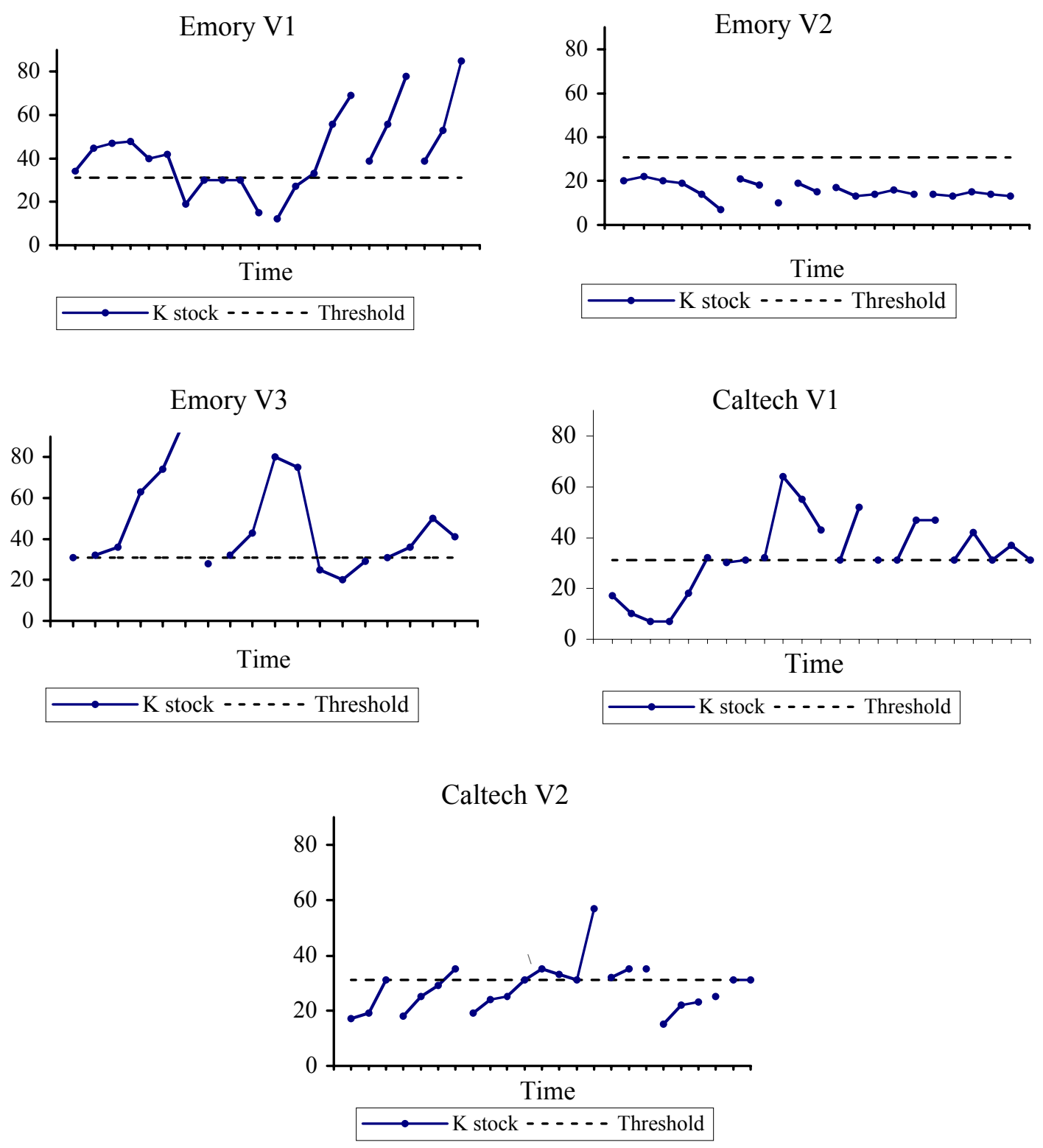
Figure 10: Observed and Threshold Level of Capital, Hybrid Treatment,

K threshold $=31$

Emory H1

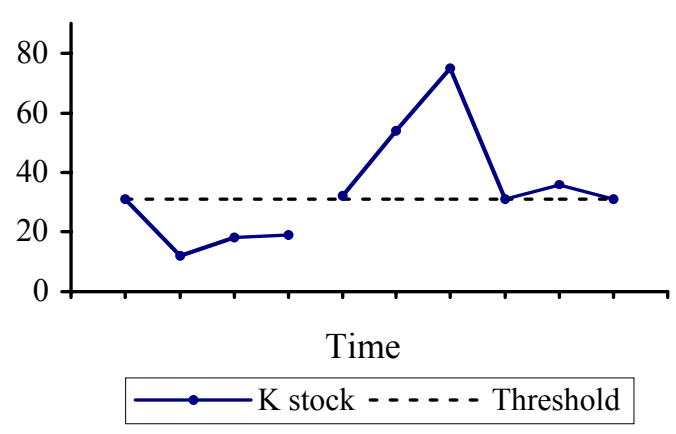

Emory H3

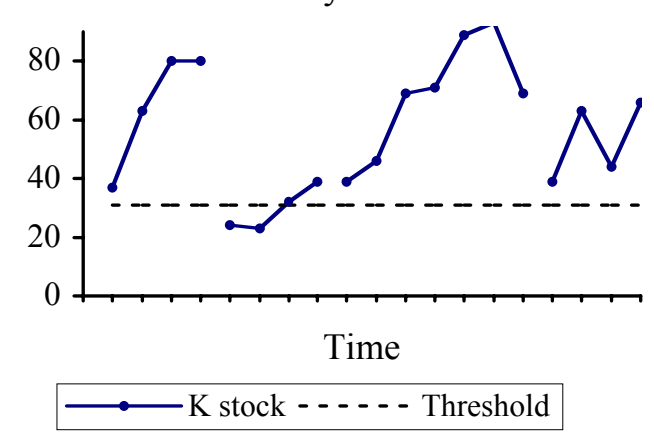

Emory H2
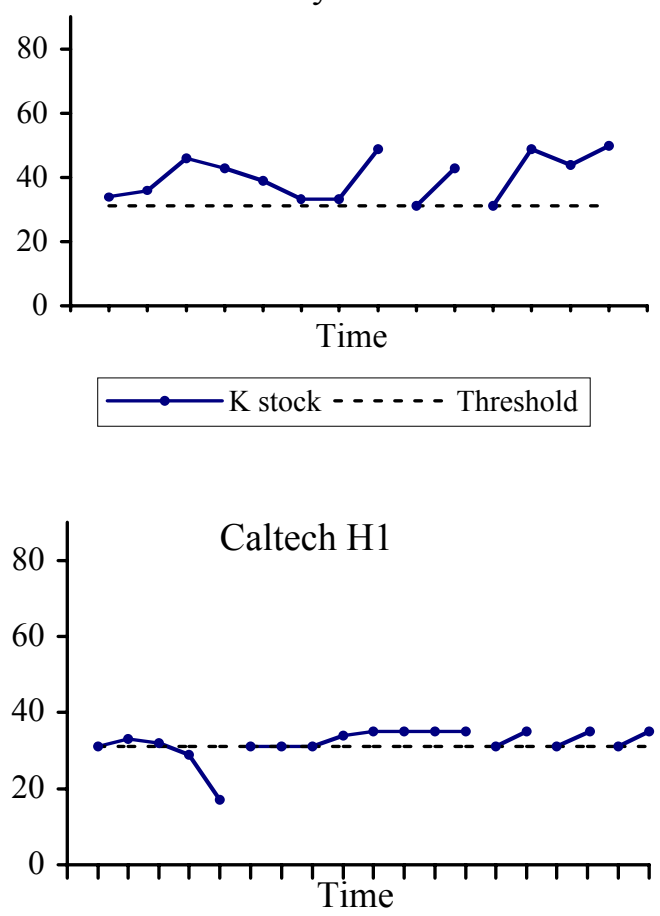

$\longrightarrow$ K stock - - - - - Threshold

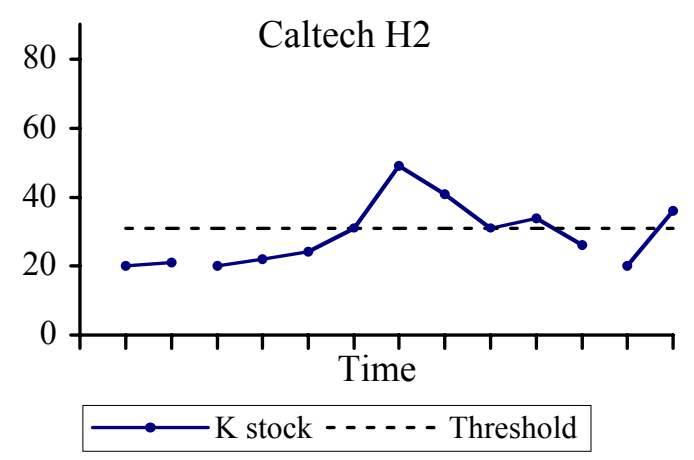


Figure 11: Convergence Values and 95\% Confidence Intervals for Capital Stock and Welfare, All Sessions and Treatments
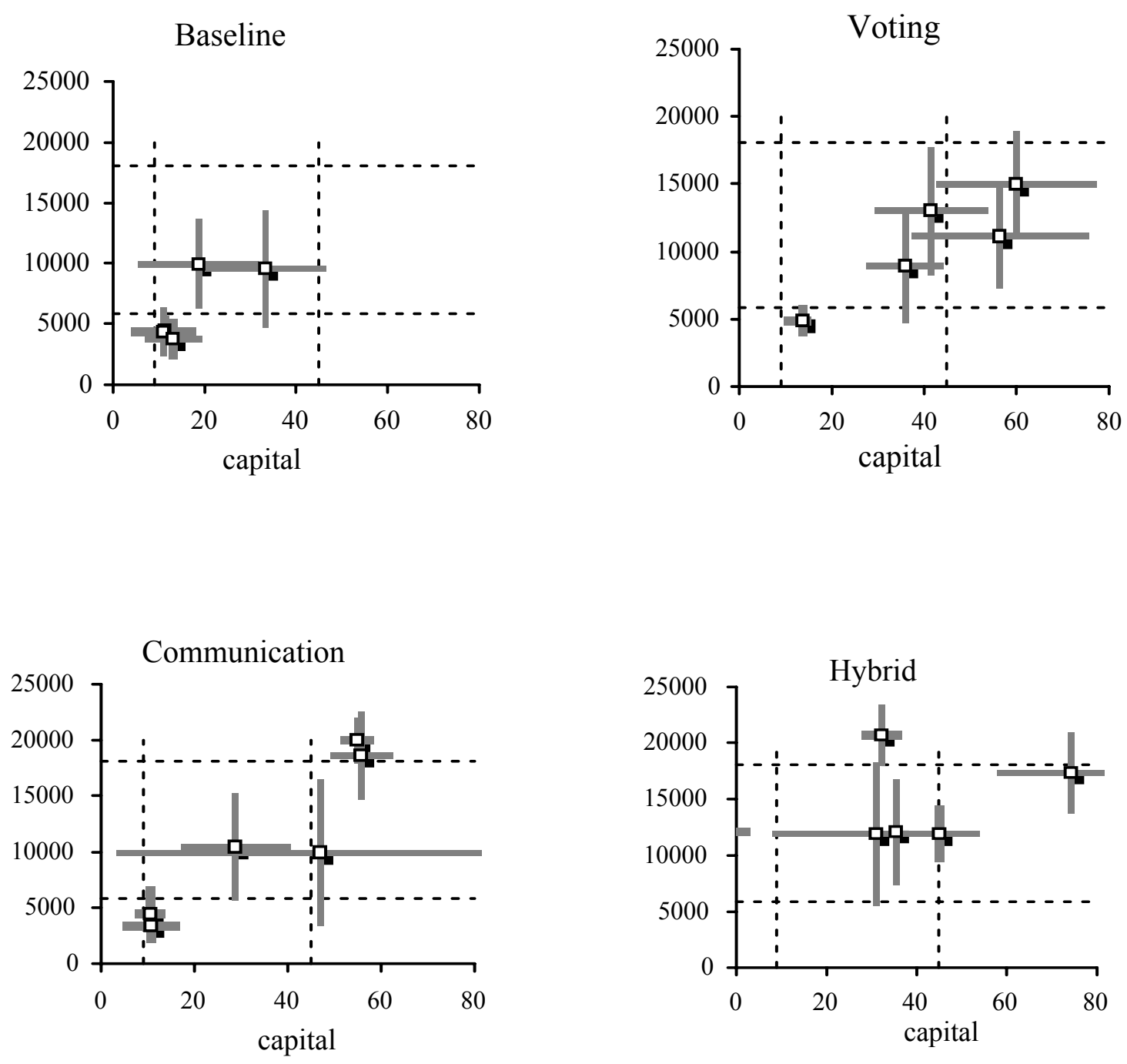
Figure 12: Observed Prices and Theoretical Predictions, Baseline Treatment
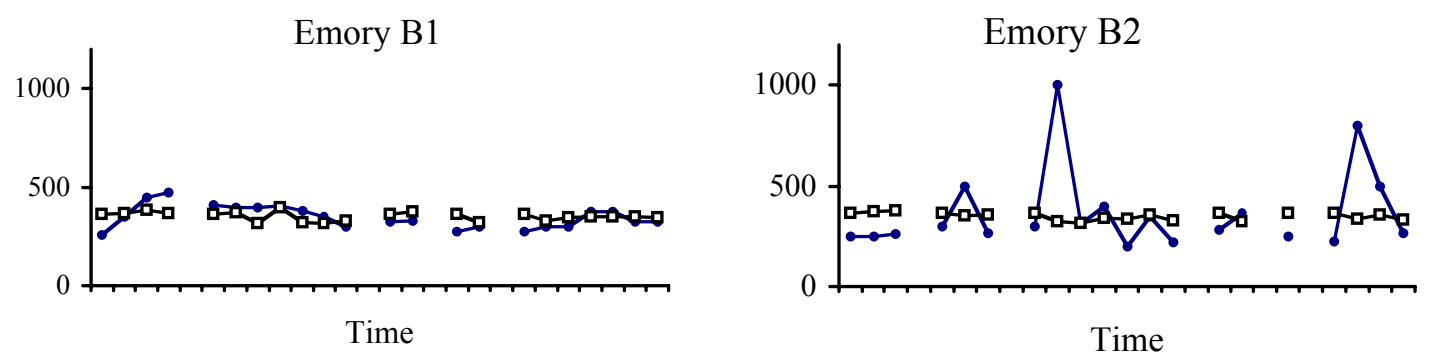

Time

$\longrightarrow$ Observed Prices —ם-Theoretical Prediction

$\longrightarrow$ Observed Prices $\longrightarrow$ - Theoretical Prediction
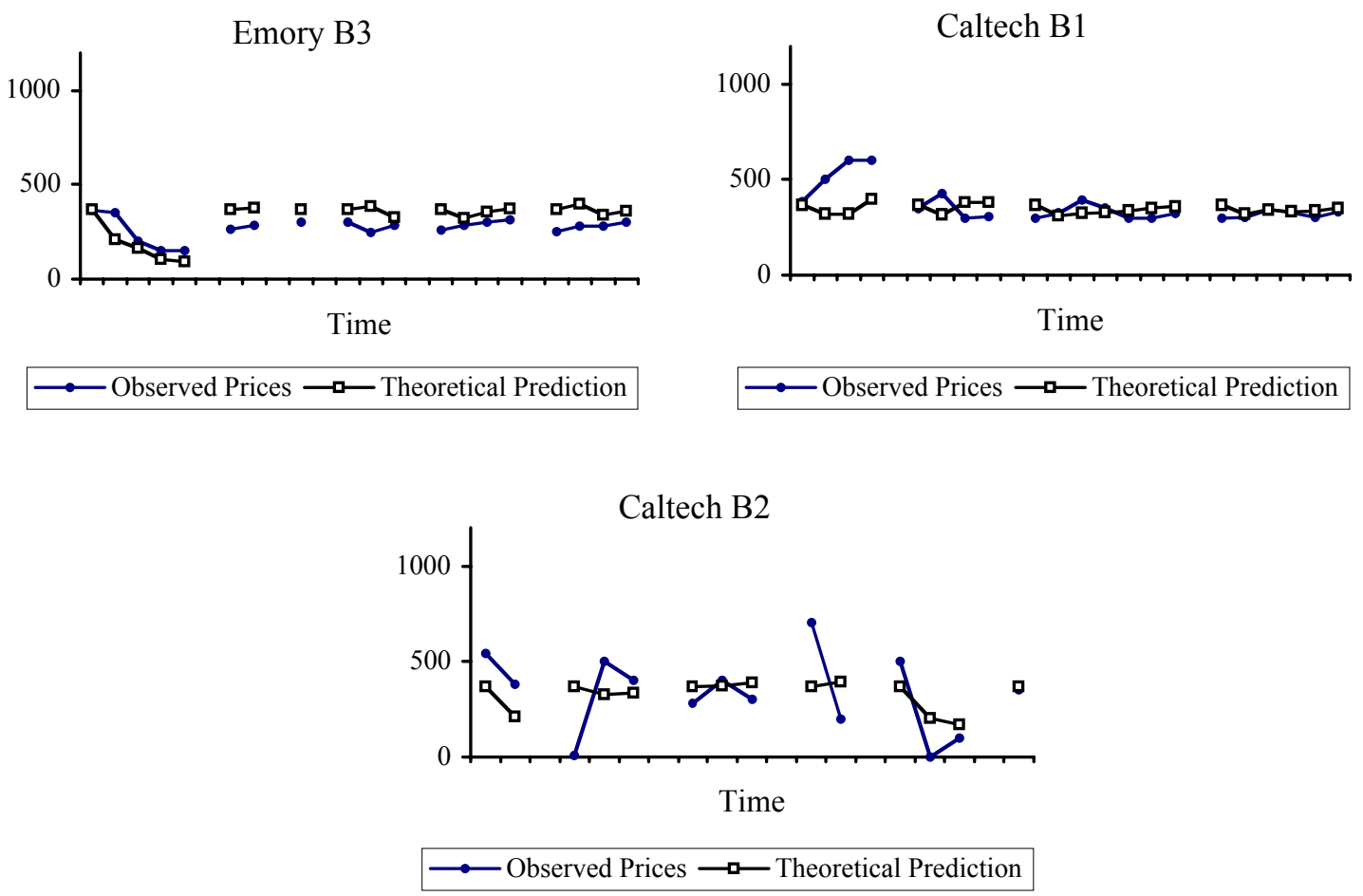
Figure 13: Observed Prices and Theoretical Predictions, Communication Treatment
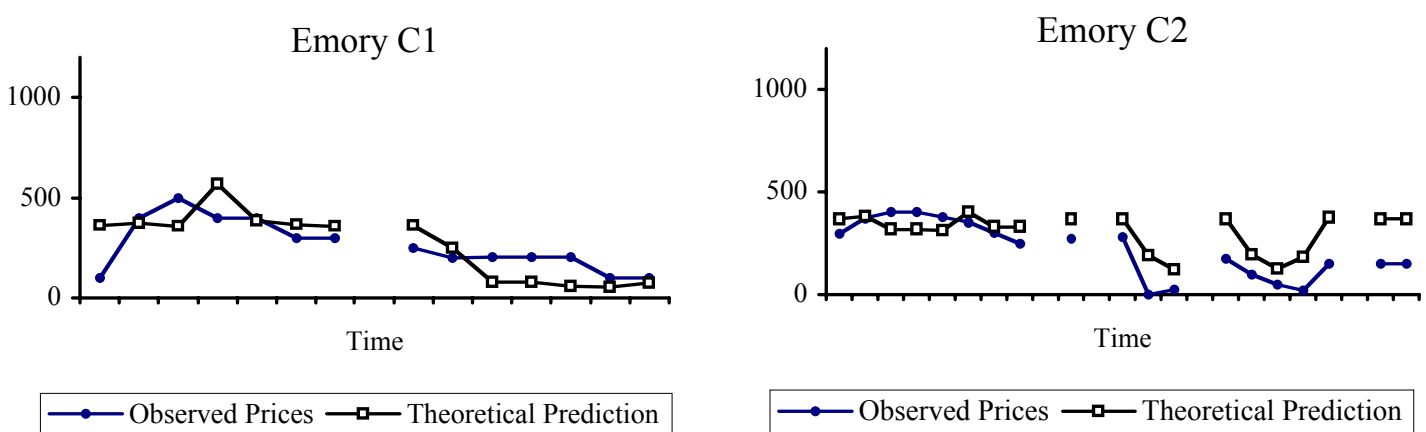

$\longrightarrow$ Observed Prices $\longrightarrow$ - Theoretical Prediction
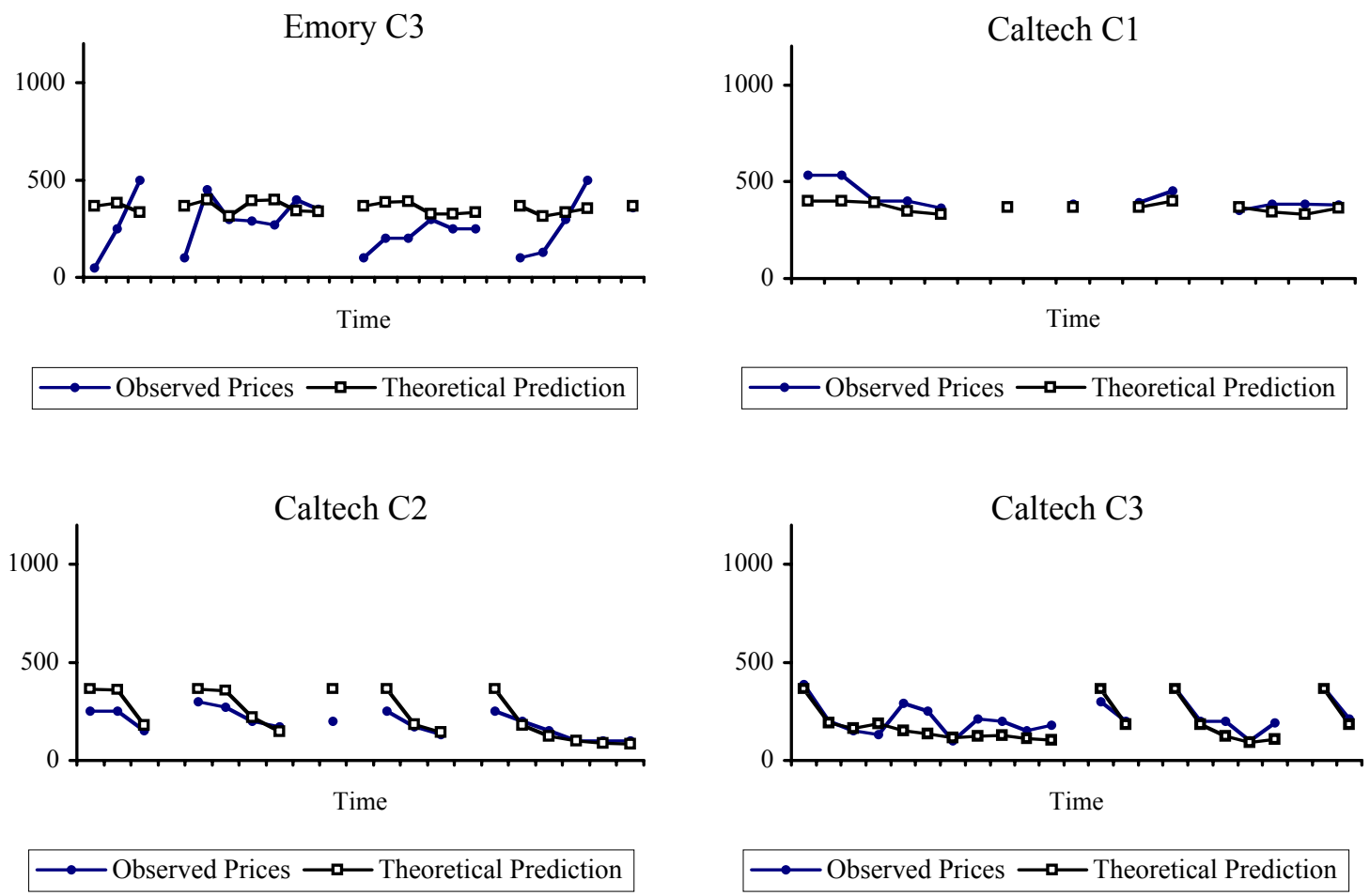
Figure 14: Observed Prices and Theoretical Predictions, Voting Treatment
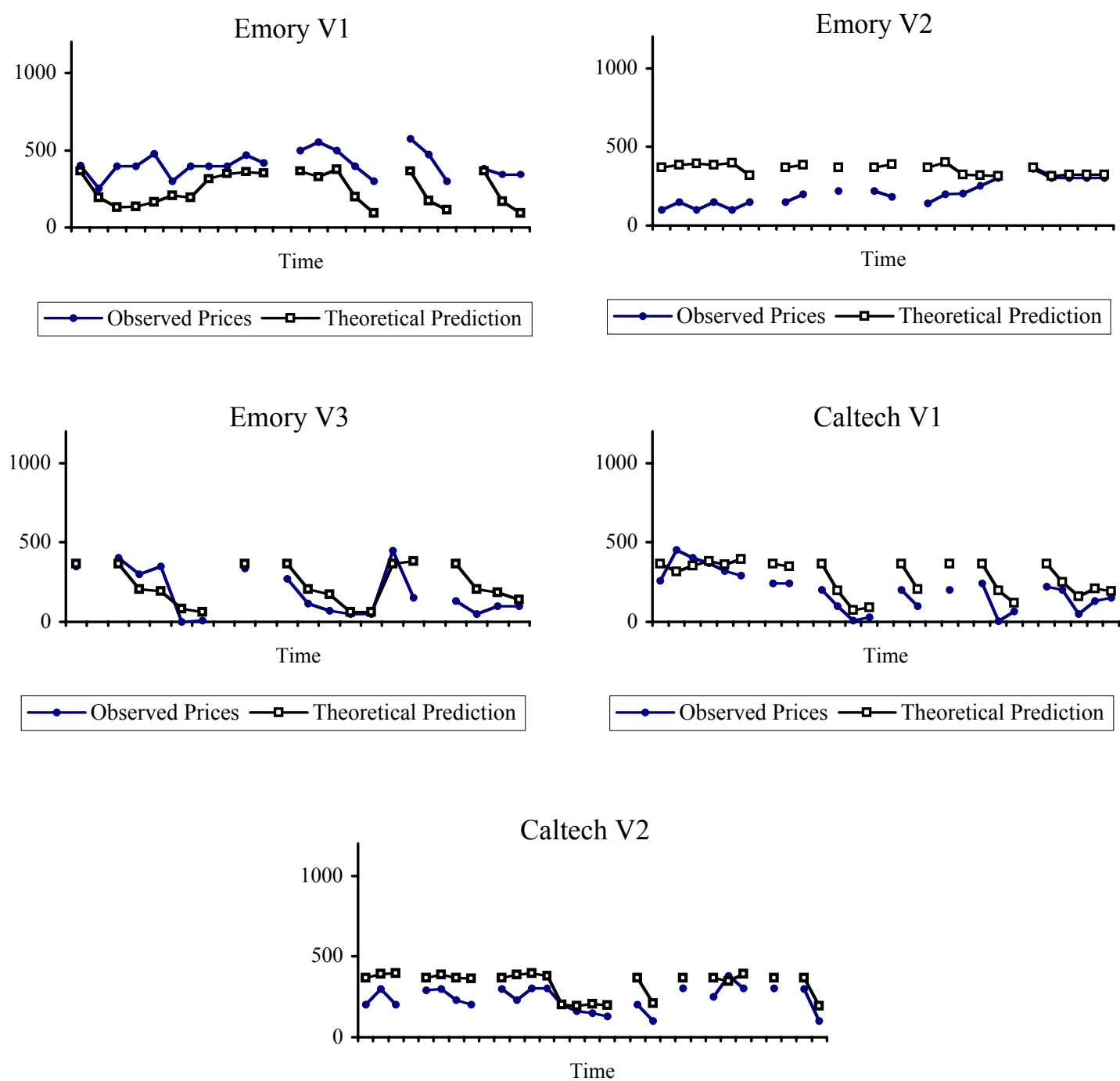

$\longrightarrow$ Observed Prices $\longrightarrow-$ Theoretical Prediction 


\section{Figure 15: Observed Prices and Theoretical Predictions, Hybrid Treatment}
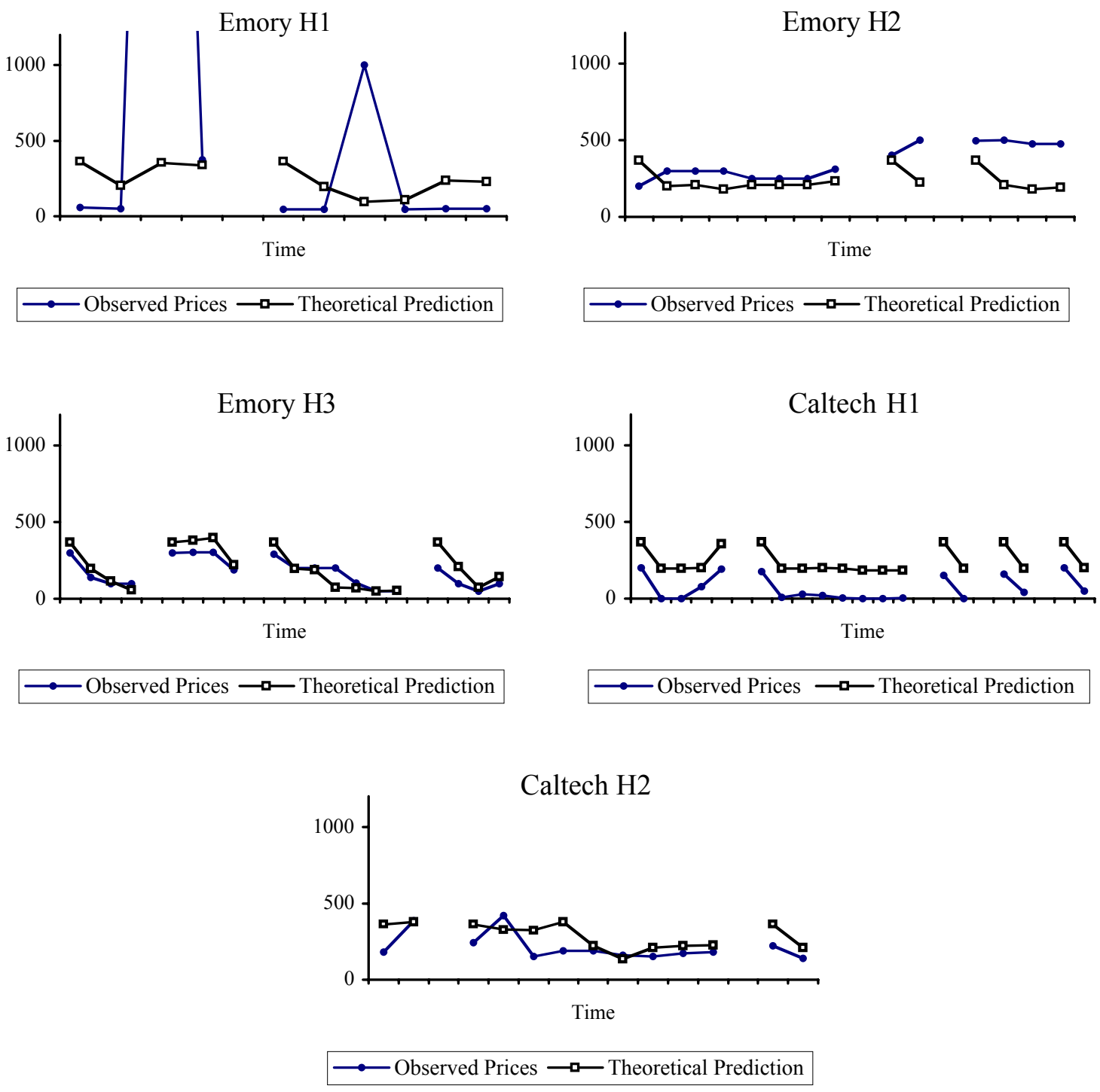
Figure 16a: Economy's Capital Stock and Number of Agents Communicating a Willingness to Coordinate Investment, Communication Treatment
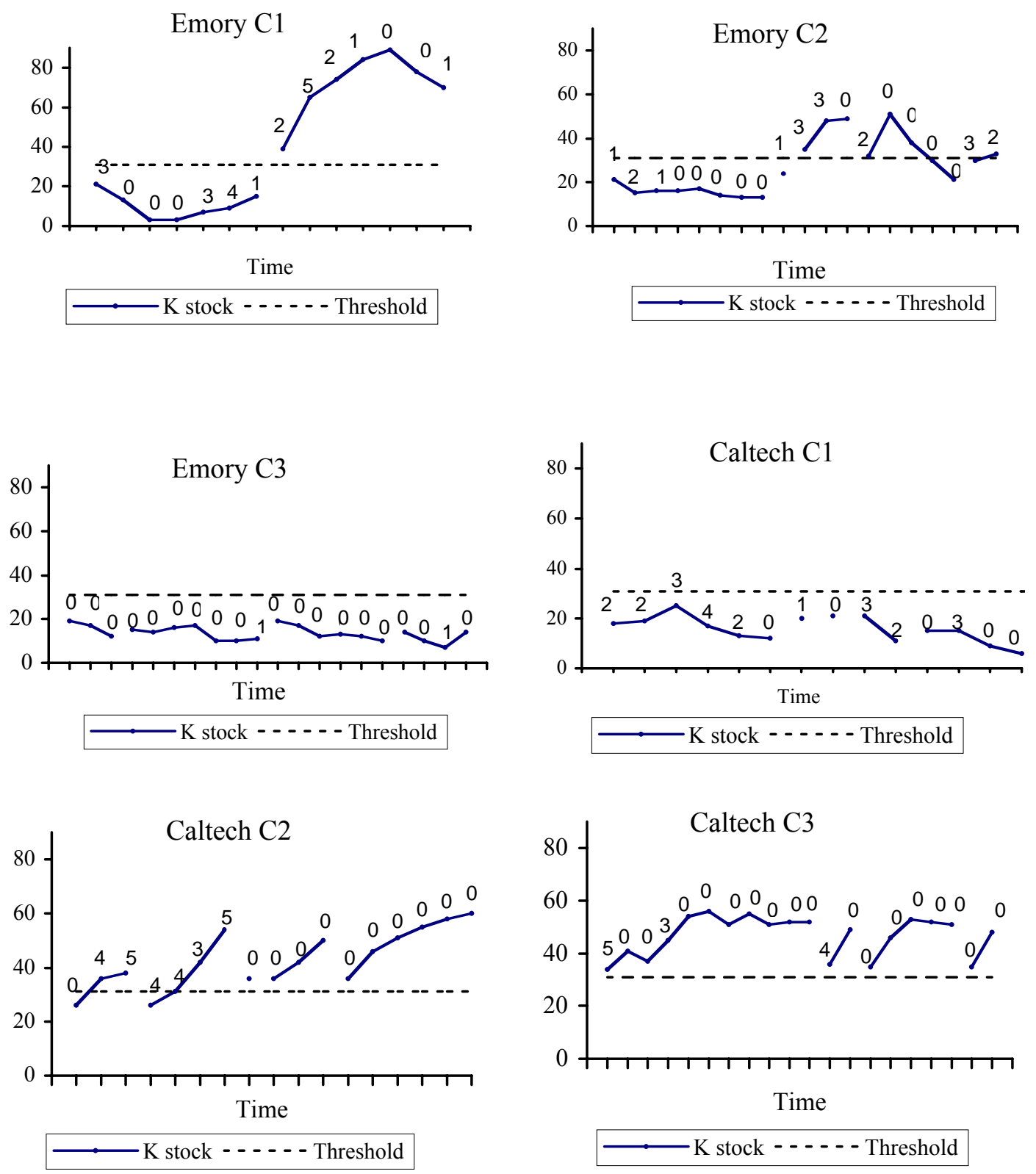
Figures 16b: Economy's Capital Stock and Number of Agents Communicating A Willingness to Coordinate Investment, Hybrid Treatment
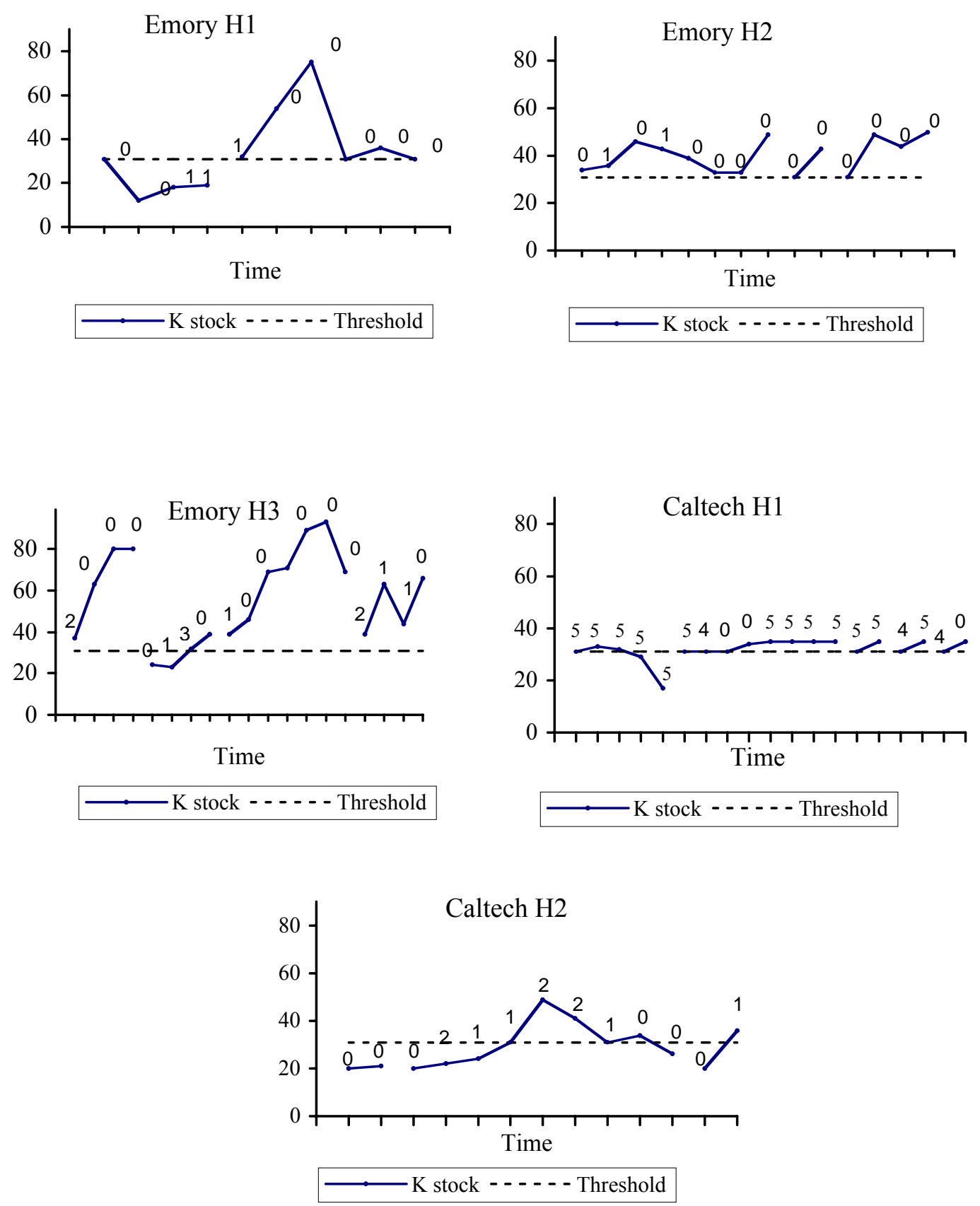


\section{Appendix}

Table A-1: Convergence Estimation Results for Capital Random-Effects MLE

Optimal Eq. Capital $=45$, Poverty Trap Capital $=9$

Coefficient $B_{2} \quad$ Std Error $\quad$ At the $5 \%$ level, convergence value significantly different from:

\begin{tabular}{ccccc}
\hline Baseline & & & Optimal Eq. & Poverty Trap \\
\hline EmoryB1 & 11.29 & 2.45 & & No \\
EmoryB2 & 10.95 & 3.12 & & No \\
EmoryB3 & 18.65 & 6.41 & & No \\
CaltechB1 & 13.14 & 2.87 & No & \\
CaltechB2 & 33.34 & 6.46 & No & \\
\hline Communication & & & & No \\
\hline EmoryC1 & 47.05 & 21.99 & & \\
EmoryC2 & 28.81 & 5.64 & & \\
EmoryC3 & 10.49 & 1.11 & & \\
CaltechC1 & 10.74 & 2.60 & & \\
CaltechC2 & 55.83 & 3.10 & & \\
CaltechC3 & 54.86 & 1.33 & & \\
\hline Voting & & & & \\
\hline EmoryV1 & 56.47 & 9.44 & No & \\
EmoryV2 & 13.74 & 1.54 & & \\
EmoryV3 & 59.96 & 8.53 & No & \\
CaltechV1 & 41.59 & 5.92 & No & \\
CaltechV2 & 35.96 & 3.96 & & \\
\hline Hybrid & & & & \\
\hline EmoryH1 & 31.08 & 11.38 & No & \\
EmoryH2 & 45.05 & 2.74 & & \\
EmoryH3 & 74.32 & 7.98 & & \\
CaltechH1 & 32.37 & 1.70 & & \\
CaltechH2 & 35.55 & 3.40 & & \\
\hline
\end{tabular}


Table A-2: Convergence Estimation Results for Welfare Random-effects MLE

\begin{tabular}{|c|c|c|c|c|}
\hline \multicolumn{5}{|c|}{ Opt. Eq. Welfare $=18,060$, Poverty Trap Welfare $=5,856$} \\
\hline Treatment & Coefficient $B_{2}$ & Std Error & \multicolumn{2}{|c|}{$\begin{array}{c}\text { At the } 5 \% \text { level, convergence value } \\
\text { significantly different from: }\end{array}$} \\
\hline Baseline & & & Optimal Eq. & Poverty Trap \\
\hline EmoryB1 & 4,436 & 428 & & \\
\hline EmoryB2 & 4,336 & 918 & & No \\
\hline EmoryB3 & 9,910 & 1,824 & & \\
\hline CaltechB1 & 3,729 & 653 & & \\
\hline CaltechB2 & 9,536 & 2,364 & & No \\
\hline \multicolumn{5}{|c|}{ Communication } \\
\hline EmoryC1 & 3,406 & 596 & & No \\
\hline EmoryC2 & 10,430 & 2,311 & & \\
\hline EmoryC3 & 4,444 & 389 & & \\
\hline CaltechC1 & 3,406 & 596 & & \\
\hline CaltechC2 & 18,576 & 1,888 & No & \\
\hline CaltechC3 & 19,952 & 902 & No & \\
\hline \multicolumn{5}{|l|}{ Voting } \\
\hline EmoryV1 & 11,118 & 1,857 & & No \\
\hline EmoryV2 & 4,885 & 411 & & No \\
\hline EmoryV3 & 14,969 & 1,920 & No & \\
\hline CaltechV1 & 13,006 & 2,294 & & \\
\hline CaltechV2 & 8,933 & 2,031 & & No \\
\hline \multicolumn{5}{|l|}{ Hybrid } \\
\hline EmoryH1 & 11,867 & 3,108 & & \\
\hline EmoryH2 & 11,900 & 1,088 & & \\
\hline EmoryH3 & 17,341 & 1,709 & No & \\
\hline CaltechH1 & 20,697 & 1,273 & No & \\
\hline CaltechH2 & 12,031 & 2,267 & & \\
\hline
\end{tabular}




\section{Table A-3: The content of communication, all sessions, communication and hybrid treatments}

\begin{tabular}{|c|c|c|}
\hline Session & & Time Observed (Horizon, Period) \\
\hline \multirow[t]{3}{*}{ EmoryC1 } & Don't Consume & $(\mathrm{H} 1,5),(\mathrm{H} 2,1)$ \\
\hline & Keep K (general) & $(\mathrm{H} 1,1),(\mathrm{H} 1,6),(\mathrm{H} 1,7),(\mathrm{H} 2,1),(\mathrm{H} 2,4)$ \\
\hline & Specific Proposal & $(\mathrm{H} 2,2),(\mathrm{H} 2,3)$ \\
\hline \multirow[t]{2}{*}{ EmoryC2 } & Don't Consume & $(\mathrm{H} 1,2),(\mathrm{H} 2,1),(\mathrm{H} 3,1),(\mathrm{H} 4,1),(\mathrm{H} 5,1),(\mathrm{H} 5,2)$ \\
\hline & Keep K (general) & $(\mathrm{H} 1,1),(\mathrm{H} 1,2),(\mathrm{H} 5,1)$ \\
\hline EmoryC3 & Don't Consume & $(\mathrm{H} 4,3)$ \\
\hline \multirow[t]{3}{*}{ CaltechC1 } & Don't Consume & $(\mathrm{H} 1,2),(\mathrm{H} 1,3)$ \\
\hline & Keep K (general) & $(\mathrm{H} 1,2),(\mathrm{H} 1,3),(\mathrm{H} 1,4),(\mathrm{H} 1,5)$ \\
\hline & Specific Proposal & $(\mathrm{H} 1,1),(\mathrm{H} 2,1),(\mathrm{H} 4,1)$ \\
\hline \multirow[t]{3}{*}{ CaltechC2 } & Don't Consume & $(\mathrm{H} 1,2),(\mathrm{H} 1,3),(\mathrm{H} 2,2)$ \\
\hline & Keep K (general) & $(\mathrm{H} 1,2),(\mathrm{H} 1,3),(\mathrm{H} 2,2),(\mathrm{H} 2,3),(\mathrm{H} 4,2)$ \\
\hline & Specific Proposal & $(\mathrm{H} 1,3),(\mathrm{H} 2,1),(\mathrm{H} 2,3),(\mathrm{H} 3,1),(\mathrm{H} 4,2)$ \\
\hline \multirow[t]{2}{*}{ CaltechC3 } & Don't Consume & $(\mathrm{H} 1,1),(\mathrm{H} 2,1)$ \\
\hline & Keep K (general) & $(\mathrm{H} 1,1),(\mathrm{H} 1,4)$ \\
\hline EmoryH1 & Keep K (general) & $(\mathrm{H} 1,3),(\mathrm{H} 1,4),(\mathrm{H} 2,1)$ \\
\hline EmoryH2 & Keep K (general) & $(\mathrm{H} 1,2)$ \\
\hline \multirow[t]{2}{*}{ EmoryH3 } & Don't Consume & $(\mathrm{H} 1,1),(\mathrm{H} 3,2),(\mathrm{H} 4,1)$ \\
\hline & Keep K (general) & $(\mathrm{H} 1,1),(\mathrm{H} 2,2),(\mathrm{H} 2,3),(\mathrm{H} 4,3)$ \\
\hline \multirow[t]{2}{*}{ CaltechH1 } & Keep K (general) & $(\mathrm{H} 1,1),(\mathrm{H} 1,3),(\mathrm{H} 1,4),(\mathrm{H} 1,5),(\mathrm{H} 2,1),(\mathrm{H} 2,2)$ \\
\hline & Specific Proposal & $\begin{array}{l}(\mathrm{H} 2,5),(\mathrm{H} 2,6),(\mathrm{H} 2,7),(\mathrm{H} 3,1),(\mathrm{H} 3,2),(\mathrm{H} 4,1),(\mathrm{H} 4,2), \\
(\mathrm{H} 5,1)\end{array}$ \\
\hline CaltechH2 & Keep K (general) & $(\mathrm{H} 2,2),(\mathrm{H} 2,4),(\mathrm{H} 3,2)$ \\
\hline
\end{tabular}


The remainder of this document contains the instructions for the baseline treatment of the experiment to aid the referees and editors in evaluating the manuscript. The instructions for communication and voting treatments were identical to the baseline's instructions, except for a section that described the chat room and the voting process, respectively. The hybrid treatment included both a chatting and a voting section. Instructions for these three treatments are available to the referees and editors upon request.

Please note that this material is not intended for publication.

\section{INSTRUCTIONS FOR THE EXPERIMENT}

\section{General Instructions}

This is an experiment in the economics of decision-making. The instructions are simple and if you follow them carefully and make good decisions, you might earn a considerable amount of money, which will be paid to you in cash at the end of the experiment. The amount of payment you receive depends partly on your decisions, partly on the decisions of others, and partly on chance. The currency used in the market is Yen. All trading will be in terms of the Yen. The cash payment to you at the end of the experiment will be in US dollars. The conversion rate is Yen to 1 US dollar.

Once the experiment has started, no one is allowed to talk to anybody other than the experimenter. Anyone who violates this rule will lose his or her right to participate in this experiment. In addition to your earnings from the activity in the experiment, you will receive a ...... payment for your participation.

\section{Basic Concepts}

The experiment will consist of a sequence of periods. At the beginning of each period, you will begin with a Cash Endowment of Yen. You will also be given good called $\mathrm{K}$ on a one-time basis at the beginning of the first period of the experiment.

In each period, there will be an open market. You will use this market to buy and sell units of K. Buying units of $\mathrm{K}$ reduces your cash by the amount of Yen that you pay for your purchases, whereas selling increases the cash you have by the amount that you receive for your sales. Thus, selling and buying $\mathrm{K}$ determines in part the earnings you make in each period.

In addition, you will have a chance to choose how many units of $\mathrm{K}$ to consume. How much of $\mathrm{K}$ you consume during a period will also in part determine your earnings for the period. The K you do not consume can grow and can be sold or consumed in future periods. 
Your earnings in a period are equal to the amount of cash you have after buying and/or selling $\mathrm{K}$ minus the cash you began the period with, plus the earnings you receive from the consumption of $\mathbf{K}$. A detailed explanation of how to buy, sell and consume units of $\mathrm{K}$ is given later on in these instructions.

Each period is divided into stages. In stage 1, you can buy and sell units of K. In stage 2, you decide how much to consume. In stage 3 , the $\mathrm{K}$ you have is converted to a different quantity of $\mathrm{K}$ that you begin the next period with.

\section{Stage 1: Buying and Selling Units of $K$}

The picture shown below is a copy of the first screen that you will see during Stage 1 of each period of the experiment. At the top of the screen you can find the Period number, the Total Earnings you have in Yen and the Remaining Time in seconds that you have to complete Stage 1. Below this information, you will find the number of Units of $K$ You Hold, indicating the number of $\mathrm{K}$ that you currently have. You will also find the Units of $K$ in the Economy, which is the total $\mathrm{K}$ that all five players currently have. You will also see the Cash Endowment for the period, indicating how much cash you currently have available for transactions.

\subsection{Sending in Limit Prices to the Market}

You will use this screen to indicate the number of units of $\mathrm{K}$ you want to trade. You do so using the spaces Units of $K$ and Limit Price. Under Units of $K$, you must enter a series of numbers in an increasing manner. The numbers will appear in the large window on the left portion of the screen. Type in a 1 for the first row, a 2 for the second row, a 3 for third row, etc... Enter as many numbers as the most units of $\mathrm{K}$ that you are willing to hold. The minimum quantity of units you can list is equal to the number of $\mathrm{K}$ you currently hold, the maximum quantity of units you can list is equal to the number of units in the economy.

In the Limit Price field you must enter a limit price for each unit you list. The role of limit prices will be explained shortly. Each unit number must be accompanied by a limit price for the unit. The limit price will also appear in the large window on the left portion of the screen. Enter the limit price next to its corresponding unit. For example, if you enter 500 next to unit 1 , it means that your limit price for the first unit is 500. If you enter a limit price of 450 next to the $2^{\text {nd }}$ unit, it means that your limit price for the second unit is 450 , and so on.

The limit price for each additional unit must be less or equal to the previous one. For example, if you list a limit price of 123 Yen for the first unit, the second unit's limit price must be equal or less than 123 Yen; similarly, the third unit's price must be less or equal to the second unit's price. All prices must be greater than zero. After entering a unit number and its corresponding limit price, you must click on Update; you will see your choices recorded in the column entitled List of your choices. At any time you can modify your choice. You can 
also select the keys Erase all choices, which clears all of your limit prices, Erase last choice, which will remove the limit price for the highest numbered unit, and Repeat, which will enter an identical price for the next unit. Once you are satisfied with your decision, you can send your limit prices to the market by clicking on Validate.

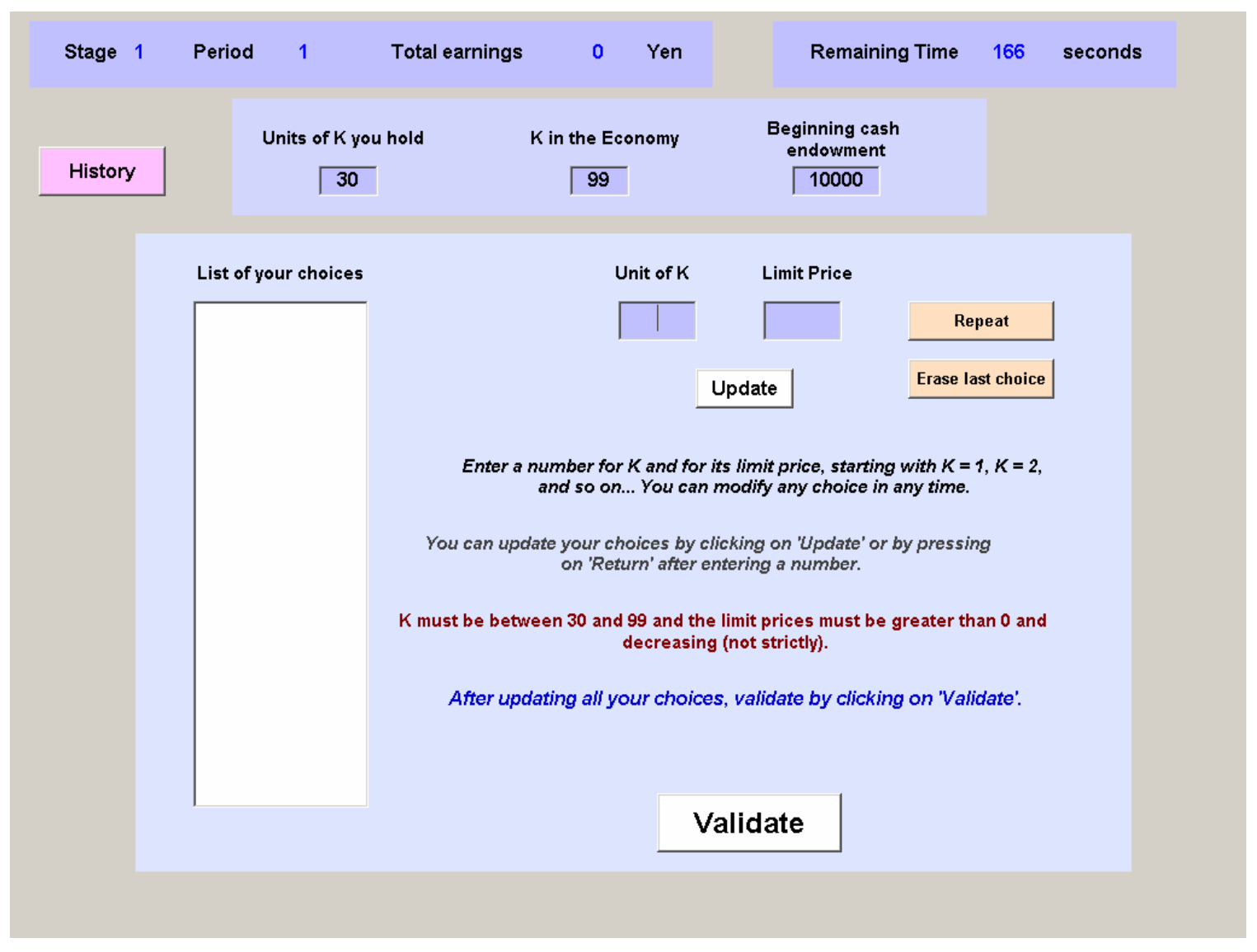

\subsection{Finding how much you buy or sell}

Whether you will buy or sell units and how much you buy or sell depends on how your limit price compares to others' limit prices, and how many units are in the economy.

After all players have entered all of their limit prices and validated them, the prices that all players have sent in are ranked together from the highest to the lowest. Those who enter the highest prices will possess the units in the economy after stage 1. For example, suppose that there are ten units in the economy. Those that send in the ten highest limit prices will then receive the ten units in the economy.

Often, the people who send in the highest limit prices will not be those who currently have the units. In that case, the people with the highest limit prices automatically purchase them from the people who currently have the units. Consider the following example. There are five players. Players 1, 2, and 3 each currently have one unit of K and players 4 and 5 do not have 
any units of K. Thus there are three units of $\mathrm{K}$ in the economy. Suppose that player 1 sends in a limit price of 500 for one unit of K. Player 2 sends in a limit price of 400 for one unit. Player 3 sends in a limit price of 600 for her first unit and 550 for her second unit. Player 4 sends in a bid of 630 for one unit. Player 5 sends in a limit price of 400 for one unit. In this example, player 3 receives two units and player 4 receives one unit of the total of three units of $\mathrm{K}$ that exist in the economy. This means that players 1 and 2 each sell one unit (they each had one before and will not have any after the market process) and players 3 and 4 each purchase one unit (player 3 had one already before the market process and player 4 did not have any).

As is clear from the above example, you are more likely to buy units for which the limit price is high and you are more likely to sell units for which the limit price is low compared to others' limit prices. Of course, at the time you choose your prices, you will not know what other players are doing. You must send in a number of limit prices that is at least as great as the number of units of $\mathrm{K}$ you currently have. To purchase units, you must send in more than that number.

\subsection{The price paid for purchases and sales}

When you are required to sell a unit you receive some cash from the sale, increasing your earnings. Likewise, when you purchase units you are required to spend cash to obtain the units, decreasing your earnings. The price at which participants buy and sell their units, which we will refer to as the market price, is determined in the following manner.

When the limit prices are ranked from highest to lowest, we take the limit price that is ranked in the spot corresponding to the number of units of $\mathrm{K}$ in the economy. This price is called the

market price. For example, for the limit prices described in the last subsection and three units in the economy, the third highest limit price submitted overall, the 550 player 3 sent in, becomes the market price. The market price is a per-unit price, so that if for example an individual buys five units, she pays five times the market price.

\section{Consuming Units of $\mathrm{K}$}

In each period, after stage 1 is completed, all players enter stage 2 . Below you will find a picture of the screen you see in Stage 2. At the top of the screen you will see the current Period, your Total Earnings in Yen for the experiment so far and the Remaining Time you have to complete this stage in seconds. The data from Stage 1 and the results from trading are also on this screen. On your screen, you will see Units of $K$ at starting, which indicates the number of units you started the period with, the Units of $K$ in the Economy, and your Cash Endowment. The screen also displays the Market Price, the price at which people bought and sold units in stage 1, K bought/sold on your part in stage 1, Cash transferred by you in stage 1 and Cash after trading, indicating how much cash you currently have. 


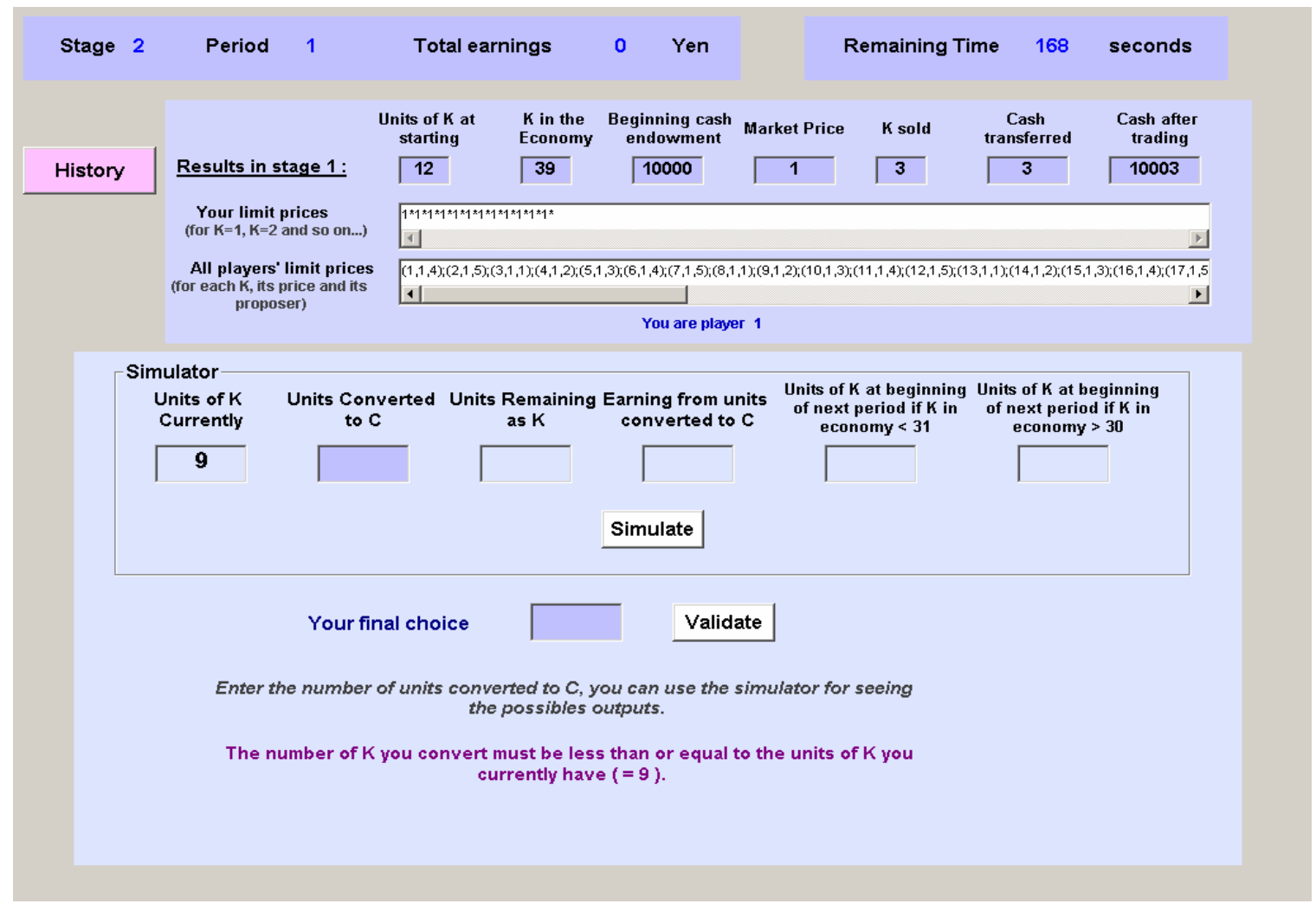

Below these columns, you will see a row called Your Limit Prices summarizing the prices that you listed in Stage 1 for each unit; starting with the limit price you sent in for your first unit, followed by the limit price for the second, etc. A star separates these prices. The second row shows All Player's Limit Prices. These are the prices that everyone in the market listed in Stage 1 for each of their units. The numbers are read in the following way. The parentheses indicate (the rank of the limit price, the limit price entered, the player who submitted the unit). They are displayed in order from the highest limit price to the lowest.

In this Stage, you need to choose how many of the units of K you currently have that you want to consume. Consuming a unit increases your earnings but removes the $\mathrm{K}$ you consume from your inventory and from the economy. How consumption affects your earnings in Yen for the period can be determined using your Redemption Value Sheet, which you received at the beginning of the experiment.

\subsection{Redemption Value Sheet and Consumption}

The Redemption Value Sheet attached to these instructions shows the value in Yen from consuming units of $\mathrm{K}$. The first column labeled Units of $K$ consumed numbers the units from 1 through 28. The column labeled Unit Value indicates the additional amount of Yen you receive from consuming the unit indicated in the same row in the first column. The column Total Value shows the total amount of Yen you receive for consuming the quantity shown in the corresponding row in the first column. Notice that if more than 20 units of $\mathrm{K}$ are consumed, the value is the same as for 20 units, indicating that there is no additional value 
from consuming more than 20 units. The computer calculates your earnings in Yen automatically; you will see the number on the Stage 2 screen shown above once you validate your choice by clicking on Validate.

You can use the table entitled Simulator to help you make your decisions. On this table, you could see how your decision of how many units of $\mathrm{K}$ to consume will affect your earnings from consumption in Yen and the remaining $\mathrm{K}$ you have for next period. In the first field, you will find your Units of $K$ Currently. In the second field, labeled Units Converted to C (C stands for consumption), you can type the number of units of $\mathrm{K}$ that you want to consume for the period. You must choose a number that is greater than or equal to 0 and less that or equal to number of units of $\mathrm{K}$ that you currently hold. After you make your decision, the remaining $\mathrm{K}$ will be recorded under Units of Remaining $K$. Under Earnings from Units Converted to $C$ you will see the value in Yen resulting from your consumption of K. Finally, the Screen also shows the Units of $K$ remaining at the beginning of next period if the economy wide $\mathrm{K}$ is less than 31 and if the economy wide $\mathrm{K}$ is greater than 30. The importance of the threshold level of $\mathrm{K}$ in the economy is explained in section 5. You can type different hypothetical amounts under Units Converted to $C$ and click on Simulate to see how much K you would have next period and what your earnings would be if you chose that level of consumption. Once you make a final decision, type your decision where it says Your Final Choice and press Validate.

\section{Production}

The remaining $\mathrm{K}$, that is, the amount of $\mathrm{K}$ that remains after you make your consumption decision, can be carried over to the next period. This $\mathrm{K}$ will be automatically converted to possibly more $\mathrm{K}$. The amount that it is converted into is based on your Production Schedule. Thus, the amount of $\mathrm{K}$ you will have at the beginning of next period depends on the remaining $\mathrm{K}$ you have after consuming at the end of the current period and on your Production Schedule.

\subsection{Production Schedule}

The Production Schedule consists of two parts. When the total amount of $K$ that the whole group has at the end of each period is less than or equal to 30 , that is when the $\mathrm{K}$ in the Economy (that is the total Remaining $\mathrm{K}$ for all five people) is less than or equal to 30 , use the left-hand-side of the Production Schedule to determine the amount of $\mathrm{K}$ that will be available to you at the beginning of next period. When the total remaining $\mathrm{K}$ in the economy exceeds 30 , then you should use the right-hand-side of the schedule. In determining which side of the schedule is used, the total Remaining $\mathrm{K}$ is measured after consumption and before it grows at the beginning of the next period.

Under the column labeled Remaining $K$ you will find the number of units of $\mathrm{K}$ you have remaining after your consumption decision. The number next to it in the column labeled $K a t$ Market Open Next Period is the amount of good K that will available to you at the beginning of next period. The calculation for determining how many units of $\mathrm{K}$ you have in the next period is done automatically by the computer. 


\section{Summary of Period Earnings}

At the end of each period, the screen you see, entitled Final Results for Period will display a summary of the activity in the period. It will indicate your earnings in Yen for the period and your total earnings in the experiment thus far. Remember that earnings for the period in Yen are given by the cash endowment remaining after trading, minus your cash endowment at the beginning of the period, plus your earnings from consumption. That is:

Earnings for a period in Yen $=$ cash endowment remaining after trading - cash endowment at the beginning of the period + period earnings from consumption

\section{Ending the Experiment}

The period in which the experiment ends is determined in the following way. Before the experiment began, the experimenter rolled a 10 -sided die a series of times to determine how long the experiment would continue. If the die came up with number 1 or 2 on the first roll, then the game will end after the first period and there are no more die rolls. Otherwise, if the die roll resulted in a number from 3 to 10, the experiment will go on to the next period, and the die is rolled again. If the die came up 1 or 2 on the second roll, the experiment will end after period 2. In other words, in any given period, there is a fixed 20 percent chance (the odds are 2 in 10) that the experiment ends right after the current period. There is always a 80 percent chance that there will be at least one more period after the current one.

However, the experiment will be restarted if it ends with more than half an hour remaining during the time for which you have been recruited. If it is restarted, you will again begin with the same number of units that you started with in period 1. On the other hand, if the experiment is still in progress at the end of the time for which you have been recruited, the experiment will be continued on another afternoon or evening. The experimenter will run another session, in which the beginning holding of $\mathrm{K}$ for each individual will be the same as the end of the current session. You are free to participate in the continuation of the session with the same ID number, picking up from where you left off today. If you choose not to continue on with the session at a later date, another participant will be recruited to take your place. The earnings of the participant filling your place will also be given to you for the remainder of the life of the current series of periods.

\section{The History Screen}

During stage 1 or stage 2, you can click on the button labeled History and you can access a history of your choices and of market activity for each past period. The information you can access includes the amount of $\mathrm{K}$ you held, the amount of $\mathrm{K}$ in the economy, your limit prices, the market price, the amount of $\mathrm{K}$ traded, the cash you have after trading, your earnings from consumption, the $\mathrm{K}$ remaining after your consumption, your period earnings, and your cumulative earnings. 